\title{
New 2-aminopyrimidine derivatives and their antitrypanosomal and antiplasmodial activities
}

\author{
Michael Hoffelner $^{1}$ - Usama Hassan ${ }^{1}$ - Werner Seebacher ${ }^{1}$ (D) . Johanna Dolensky ${ }^{1}$. Patrick Hochegger ${ }^{1}$. \\ Marcel Kaiser ${ }^{2} \cdot$ Pascal Mäser $^{2} \cdot$ Robert Saf $^{3} \cdot$ Robert Weis $^{1}$
}

Received: 19 June 2020 / Accepted: 10 August 2020 / Published online: 11 September 2020

(c) The Author(s) 2020

\begin{abstract}
Novel 2-aminopyrimidine derivatives were prepared from acyclic starting materials, benzylidene acetones and ammonium thiocyanates, via 5 steps, including ring closure, aromatization, $S$-methylation, oxidation to methylsulfonyl compounds, and formation of guanidines with suitable amines. The prepared compounds differ from each other by the substitutions of their amino group and of their phenyl ring. The 2-aminopyrimidines were tested by use of microplate assays for their in vitro activities against a causative organism of sleeping sickness, Trypanosoma brucei rhodesiense, as well as against a causative organism of malaria, Plasmodium falciparum NF54. Their cytotoxic properties were determined with L-6 cells (rat skeletal myoblasts). Some of the compounds exhibited quite good antitrypanosomal activity, and others showed excellent antiplasmodial activity. The influence of the structural modifications on these activities is discussed.
\end{abstract}

Graphic abstract

(c)

Keywords Antiplasmodial activity $\cdot$ Antitrypanosomal activity $\cdot$ Heterocycles $\cdot$ Drug research $\cdot$ Structure-activity relationships

Electronic supplementary material The online version of this article (https://doi.org/10.1007/s00706-020-02674-7) contains supplementary material, which is available to authorized users.

Werner Seebacher

we.seebacher@uni-graz.at

1 Institute of Pharmaceutical Sciences, University of Graz, Graz, Austria

2 Swiss Tropical and Public Health Institute and University of Basel, Basel, Switzerland

3 Institute for Chemistry and Technology of Materials (ICTM), Graz University of Technology, Graz, Austria

\section{Introduction}

In the past two decades, over two billion of the world's poorest people have been affected by neglected tropical diseases (NTDs). One of the 11 major NTDs studied is human African trypanosomiasis (HAT) [1]. HAT or sleeping sickness is caused by protozoa of the genus Trypanosoma like Trypanosoma brucei gambiense (Tbg) and Trypanosoma brucei rhodesiense (Tbr). The vector is the tsetse fly. Only one drug, melarsoprol, is available for the late-stage Tbr infection treatment [2]. This toxic arsenic compound causes severe side effects including a deadly encephalopathy in more than $5 \%$ of the patients [3]. Therefore it is an urgent 
need to develop new efficient antitrypanosomal compounds with less side effects.

In 2018 malaria globally affected 228 million people and caused 405,000 deaths [4]. The emergence and spread of resistance in Plasmodium falciparum malaria to artemisinin combination therapies in the Greater Mekong subregion poses a major threat to malaria control and elimination [5]. Since the last defense line, the artemisinines, might fall possibly, there is a great demand for antiplasmodial compounds with alternative mechanism of action.

Substituted pyrimidines were described early as antiplasmodial compounds [6-12]. Some 2-aminopyrimidines were reported to be active in low micromolar to submicromolar concentration [13]. We prepared new methyl-aryl-substituted 2-aminopyrimidines including compounds bearing partial structures of chloroquine which were connected to the nitrogen in ring position 2 .

\section{Results and discussion}

Starting from benzylidene acetones 1a-1d pyrimidinethiones $\mathbf{2 a - 2 d}$ were prepared by reaction with ammonium thiocyanate in refluxing benzene/cyclohexanol [14]. Aromatization of the heterocyclic ring took place in boiling xylene in the presence of sulfur giving compounds 3a-3d. Subsequently the $\mathrm{SH}$ group was methylated using methyl iodide in chloroform yielding $\mathbf{4 a}-\mathbf{4 d}$. The next step was an oxidation to the methylsulfonyl compounds $\mathbf{5 a - 5 d}$ with $m$-chloroperbenzoic acid in dichloromethane. The final formation of the target compounds $\mathbf{6}-\mathbf{1 0}$ took place in dioxane or tetrahydrofuran in the presence of the various amines under microwave irradiation at $120{ }^{\circ} \mathrm{C}$ or under reflux. Structural modifications were restricted to the amino substituent including amino, a (pyrrolidin-1-yl) and (4-methylpiperazin1-yl) groups of compounds 6-8. Moreover, partial structures of chloroquine were used as substituents for compounds 9 and 10. The chiral aliphatic amine moiety was connected with the pyrimidine core giving compounds 9 as racemates. In a further step, the quinoline residue was attached. Similar compounds, bearing an additional ester function have already been investigated [15]. Further variations concerned the substitution pattern of a phenyl ring (Scheme 1).

Scheme 1. Syntheses of compounds 2-10. Reagents and conditions: (i) benzene, cyclohexanol, water separator, reflux, $6 \mathrm{~h}$, (ii) S, xylene, reflux, overnight, (iii) $\mathrm{CH}_{3} \mathrm{I}, \mathrm{CHCl}_{3}$, r.t., overnight to 3 days, (iv) m-chloroperbenzoic acid, $\mathrm{CH}_{2} \mathrm{Cl}_{2}$, 0-20 ${ }^{\circ} \mathrm{C}, 2 \mathrm{~h}$, (v) $\mathrm{NH}_{3}$ conc. or amine, dioxane or THF, $85^{\circ} \mathrm{C}$, reflux overnight or microwave $120^{\circ} \mathrm{C} 2-13 \mathrm{~h}$. For the aromatization from 2a-2d to 3a-3d we observed the disappearance of the proton signal at $4.9 \mathrm{ppm}$ of the $\mathrm{CH}$ group attached to the aromatic moiety in ${ }^{1} \mathrm{H}$ NMR spectra as well as the shift of the signal of the olefinic proton from $4.7 \mathrm{ppm}$ to $7.3 \mathrm{ppm}$. Furthermore, the signals of the $\mathrm{NH}$ protons at 8.8 and $9.5 \mathrm{ppm}$

Scheme 1<smiles>[R]c1ccc(/C=C/C(C)=O)cc1</smiles>

6a-6d: $\mathrm{R}^{2}=\mathrm{R}^{3}=\mathrm{H}$

7a-7d: $R^{2}+R^{3}=-\left(\mathrm{CH}_{2}\right)_{4}^{-}$

8a-8d: $R^{2}+R^{3}=-\left(\mathrm{CH}_{2}\right)_{2}-\mathrm{N}\left(\mathrm{CH}_{3}\right)-\mathrm{CH}_{2}-\mathrm{CH}_{2}-$

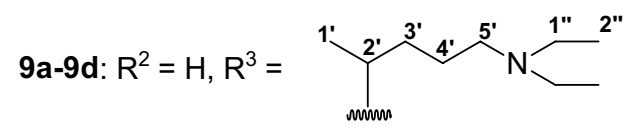

10a-10d: $R^{2}=H, R^{3}=$<smiles>CC[C@H](C)CN</smiles>

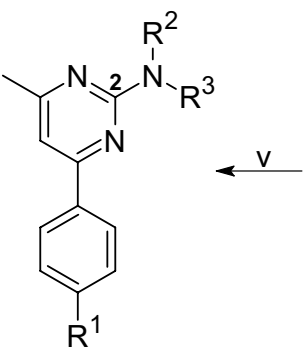

6-10 iv<smiles>[R]c1ccc(-c2cc(C)nc(S(C)(=O)=O)n2)cc1</smiles>

$5 a-5 d$ 
disappeared and a new signal was observed for the $\mathrm{SH}$ group at $13.5 \mathrm{ppm} . \mathrm{In}{ }^{13} \mathrm{C}$ spectra, the signal of the carbon attached to the aromatic moiety shifted from 54 to $165 \mathrm{ppm}$ due to aromatization. $S$-Methylation to compounds $\mathbf{4 a}-\mathbf{4 d}$ caused appearance of an additional signal at $2.6 \mathrm{ppm}$ for the methylthio group in ${ }^{1} \mathrm{H}$ NMR spectra and at $13.8 \mathrm{ppm}$ in ${ }^{13} \mathrm{C}$ spectra. The subsequent oxidation to the methylsulfonyl group in $\mathbf{5 a - 5 d}$ shifted the signal of the attached methyl group from $2.6 \mathrm{ppm}$ to $3.4 \mathrm{ppm}$ in ${ }^{1} \mathrm{H}$ NMR spectra and from $13.8 \mathrm{ppm}$ to $39 \mathrm{ppm}$ in ${ }^{13} \mathrm{C}$ spectra. The replacement of the methylsulfonyl group of compunds $\mathbf{5 a}-\mathbf{5 d}$ by amino substituents shifted the signal for the C-2 2-6 ppm to lower frequencies. Moreover, we observed long-range couplings from protons of the amino substituent to C-2 in HMBC spectra of compounds $\mathbf{6}-\mathbf{- 1 0}$ which confirmed the attachment of the amino groups to this ring position.

All 2-aminopyrimidine derivatives $\mathbf{6}-\mathbf{- 1 0}$ were tested for their antiplasmodial activities against $P$. falciparum NF54 and for their antitrypanosomal potencies against Trypanosoma brucei rhodesiense STIB 200 as well as for their cytotoxicity against rat skeletal myoblasts (L-6 cells) in microplate assays. The results are presented in Table 1 .

A series of 4-alkyl-6-(hetero)arylpyrimidin-2-amines was reported to possess promising antiplasmodial activity $\left(\mathrm{IC}_{50}=0.115-3.96 \mu \mathrm{M}\right)$; however, the significance of the results was not sustained by cytotoxicity data [13]. Our 2-amino compounds 6a-6d, 7a-7d, and 8a-8d were completely inactive $\left(\mathrm{IC}_{50}=11.2-270 \mu \mathrm{M}\right)$ against $P$. falciparum NF54. The by far lower activity of our 6-methyl compound 6b $\left(\mathrm{IC}_{50}=139 \mu \mathrm{M}\right)$ compared to its 6-isopropyl analogue $\left(\mathrm{IC}_{50}=3.96 \mu \mathrm{M}\right)$ [13] may be explained by the use of different strains test methods. The substitution of the amino group with the side chain of chloroquine improved the antiplasmodial activity $\left(9 \mathbf{a}-9 \mathrm{c}\right.$ : $\left.\mathrm{IC}_{50}=2.62-73.0 \mu \mathrm{M}\right)$ only slightly. Moreover, the selectivity indexes of compounds $\mathbf{6}-\mathbf{9}\left(\mathrm{SI}_{\mathrm{PN}}=1.08-7.84\right)$ were very low. High activity against $P$. falciparum NF54 $\left(\mathrm{IC}_{50}=0.04-0.14 \mu \mathrm{M}\right)$ and good selectivity $\left(\mathrm{SI}_{\mathrm{PN}}=81-220\right)$ was observed for the 2-aminopyrimidines 10a-10d, which exhibit a 4-aminoquinoline partial structure linked to their amino nitrogen. The most active compound 10d was additionally tested against the multiresistant $K_{1}$ strain of $P$. falciparum and showed slightly decreased activity $\left(\mathrm{IC}_{50}=0.14 \mu \mathrm{M}\right)$ but is more active than chloroquine $\left(\mathrm{IC}_{50}=0.27 \mu \mathrm{M}\right)[16]$ against this strain.

Most of the new compounds exhibited weak or negligible antitrypanosomal activity $\left(\mathrm{IC}_{50}=6.20-214 \mu \mathrm{M}\right)$ or low selectivity $\left(\mathrm{SI}_{\mathrm{T}}=0.68-5.78\right)$ or both of them. However, moderate activity $\left(\mathrm{IC}_{50}=1.90,2.40 \mu \mathrm{M}\right)$ and quite good selectivity $\left(\mathrm{SI}_{\mathrm{T}}=17.4,25.5\right)$ were observed for compounds $\mathbf{8 b}, \mathbf{8 c}$ with 4-methylpiperazinyl substitution. The most promising antitrypanosomal compounds $\mathbf{9 b}$ and $\mathbf{9 c}\left(\mathrm{IC}_{50}=0.41,1.03 \mu \mathrm{M}\right.$; $\left.\mathrm{SI}_{\mathrm{T}}=30.7,30.9\right)$ feature the side chain of chloroquine.
Table 1 Antiprotozoal and cytotoxic activities of compounds 6-10 $\left(\mathrm{IC}_{50}\right.$ values in $\left.\mu \mathrm{M}\right)$

\begin{tabular}{|c|c|c|c|c|c|}
\hline \multirow[t]{2}{*}{ Cpd } & \multirow{2}{*}{$\begin{array}{l}L-6 \text { cells } \\
\mathrm{IC}_{50}{ }^{\mathrm{a}}\end{array}$} & \multicolumn{2}{|c|}{ P. falciparum NF54 } & \multicolumn{2}{|c|}{ T. b. rhodesiense } \\
\hline & & $\mathrm{IC}_{50}^{\mathrm{a}}$ & $\mathrm{SI}_{\mathrm{PN}}^{\mathrm{b}}$ & $\mathrm{IC}_{50}^{\mathrm{a}}$ & $\mathrm{SI}_{\mathrm{T}}^{\mathrm{c}}$ \\
\hline $6 \mathbf{a}$ & 304 & 270 & 1.12 & 172 & 1.77 \\
\hline $6 \mathbf{b}$ & 439 & 139 & 3.16 & 75.9 & 5.78 \\
\hline $6 c$ & 270 & 112 & 2.41 & 92.3 & 2.93 \\
\hline 6d & 465 & 204 & 2.28 & 37.9 & 12.3 \\
\hline $7 \mathbf{a}$ & 215 & 86.9 & 2.47 & 214 & 1.00 \\
\hline $7 b$ & 107 & 22.7 & 4.71 & 158 & 0.68 \\
\hline $7 c$ & 178 & 22.7 & 7.84 & 210 & 0.85 \\
\hline 7d & 178 & 35.3 & 5.04 & 185 & 0.96 \\
\hline $8 \mathbf{a}$ & 89.4 & 41.0 & 2.18 & 7.00 & 12.8 \\
\hline $8 b$ & 33.1 & 11.2 & 2.96 & 1.90 & 17.4 \\
\hline $8 \mathrm{c}$ & 61.1 & 11.8 & 5.18 & 2.40 & 25.5 \\
\hline $8 d$ & 70.2 & 29.6 & 2.37 & 6.20 & 11.3 \\
\hline $9 \mathbf{a}$ & 59.3 & 16.5 & 3.59 & 6.43 & 9.22 \\
\hline $9 b$ & 12.6 & 2.62 & 4.81 & 0.41 & 30.7 \\
\hline $9 c$ & 31.8 & 5.52 & 5.76 & 1.03 & 30.9 \\
\hline 9d & 78.8 & 73.0 & 1.08 & 6.93 & 11.4 \\
\hline $10 \mathrm{a}$ & 19.6 & 0.14 & 140 & 8.62 & 2.28 \\
\hline $10 \mathrm{~b}$ & 9.90 & 0.045 & 220 & 4.22 & 2.35 \\
\hline $10 \mathrm{c}$ & 14.3 & 0.10 & 143 & 4.90 & 2.92 \\
\hline 10d & 3.24 & 0.04 & 81 & 3.98 & 0.81 \\
\hline $\mathrm{Mel}^{\mathrm{d}}$ & 7.78 & & & 0.0039 & 1995 \\
\hline $\mathrm{CQ}^{\mathrm{e}}$ & 116.9 & 0.007 & 16,700 & & \\
\hline$P^{f}$ & 0.012 & & & & \\
\hline
\end{tabular}

${ }^{a}$ Values represent the average of four determinations (two determinations of two independent experiments) indicated in $\mu \mathrm{M}$

${ }^{\mathrm{b}}$ Selectivity index for $P$. falciparum NF54 $\left(\mathrm{SI}_{\mathrm{PN}}\right)$, expressed as ratio $\left[\mathrm{IC}_{50}(\mathrm{~L} 6) / \mathrm{IC}_{50}(P\right.$. falciparum $\left.\mathrm{NF} 54)\right]$

${ }^{\mathrm{c}}$ Selectivity index for $T$. b. rhodesiense $\left(\mathrm{SI}_{\mathrm{T}}\right)$, expressed as ratio $\left[\mathrm{IC}_{50}(\mathrm{~L} 6) / \mathrm{IC}_{50}\right.$ (T. b. rhodesiense)]. Reference compounds (Fig. 1)

${ }^{\mathrm{d}} \mathrm{Mel}$, melarsoprol

${ }^{\mathrm{e}} \mathrm{CQ}$, chloroquine diphosphate

${ }^{\mathrm{f}} \mathrm{P}$, podophyllotoxin

\section{Conclusion}

Several new methyl-aryl-substituted 2-aminopyrimidines with differing amino and phenyl substitution have been prepared. The antitrypanosomal and antiplasmodial activities of the new compounds were determined. The most active antitrypanosomal compounds $\left(\mathrm{IC}_{50}=0.41\right.$, $1.03 \mu \mathrm{M})$ exhibited the same side chain as chloroquine. Compounds possessing the 7 -chloroquinoline partial structure of chloroquine showed excellent activity against P. falciparum NF54 $\left(\mathrm{IC}_{50}=0.04-0.14 \mu \mathrm{M}\right)$. The most 
Fig. 1 Structures of reference compounds<smiles>CCN(CC)CCCC(C)Nc1ccnc2cc(Cl)ccc12</smiles>

chloroquine<smiles>COc1cc(C2c3cc4c(cc3C(O)C3COC(=O)C23)OCO4)cc(OC)c1OC</smiles>

melarsoprol<smiles>Nc1nc(N)nc(Nc2ccc([As]3SCC(CO)S3)cc2)n1</smiles>

podophyllotoxin

active compound was additionally tested against the multiresistant $K_{1}$ strain of P. falciparum and showed twice the activity of chloroquine against this strain. Therefore, this compound could be a lead for further optimization.

\section{Experimental}

Melting points were obtained on a digital melting point apparatus Electrothermal IA 9200. IR spectra: Bruker Alpha Platinum ATR FT-IR spectrometer ( $\mathrm{KBr}$ discs). NMR spectra: Varian Inova $400(300 \mathrm{~K}) 5 \mathrm{~mm}$ tubes, spectra were acquired in $\mathrm{CDCl}_{3}$ containing $0.03 \%$ TMS. Chemical shifts were recorded in parts per million ( $\mathrm{ppm})$, for ${ }^{1} \mathrm{H}$ spectra TMS $(0.00 \mathrm{ppm})$ was used as internal standard and for ${ }^{13} \mathrm{C}$ spectra the central peak of the $\mathrm{CDCl}_{3}$ peak was used as the internal reference $(77.0 \mathrm{ppm})$. Some spectra were acquired in DMSO- $d_{6}$. Here the proton signal at $2.49 \mathrm{ppm}$ served as internal reference as well as the central peak of the DMSO$d_{6}$ signal at $39.7 \mathrm{ppm}$. Abbreviations: aromatic $\mathrm{H}, \mathrm{ArH}$; aromatic $\mathrm{C}, \mathrm{ArC}$, quaternary aromatic $\mathrm{C}, \mathrm{ArC}_{\mathrm{q}}$. Signal multiplicities are abbreviated as follows: s, singlet; $\mathrm{d}$, doublet; t, triplet; m, multiplet; q, quartet; br, broad. Coupling constants $(J)$ are reported in Hertz $(\mathrm{Hz}) .{ }^{1} \mathrm{H}$ and ${ }^{13} \mathrm{C}$ resonances were assigned using ${ }^{1} \mathrm{H},{ }^{1} \mathrm{H}$ - and ${ }^{1} \mathrm{H},{ }^{13} \mathrm{C}$-correlation spectra. ${ }^{1} \mathrm{H}$ and ${ }^{13} \mathrm{C}$ resonances are numbered as given in the formulae. Assignments marked with an asterisk are interchangeable. HRMS: GCT-Premier, Waters (EI, $70 \mathrm{eV}$ ). Materials: column chromatography (CC): silica gel 60 (Merck 70-230 mesh, pore-diameter $0.6 \mathrm{~nm}$ ), aluminium oxide (Alox) basic (Fluka for chromatography, 0.05-0.15 mm, Brockmann activity I, basic); Alox neutral 90 (Merck, 0.063-0.2 mm, activity I, neutral); thin-layer chromatography (TLC): TLC plates (Merck, silica gel $60 \mathrm{~F}_{254} 0.2 \mathrm{~mm}, 200 \times 200 \mathrm{~mm}$ ); TLC plates (Merck, Alox $60 \mathrm{~F}_{254}$ neutral, $200 \times 200 \mathrm{~mm}$ ); the substances were detected in UV light at $254 \mathrm{~nm}$. Unless otherwise stated silica gel was used for separations (CC, TLC). Microwave-assisted reactions were carried out in a CEM Discover/Explorer system in sealed $10 \mathrm{~cm}^{3}$ standard vessels with temperature control. Syntheses of compounds 2a, 2b, and 2d were described previously [14]. Compund 3a was prepared following a reported procedure [17]. Its melting point $\left(201-205^{\circ} \mathrm{C}\right)$ corresponded well with the reported one $\left(202-204{ }^{\circ} \mathrm{C}\right)$ [18]. The synthesis of $\mathbf{4 a}$ was already described and the melting point $\left(214^{\circ} \mathrm{C}\right)$ corresponded well with the reported one $\left(213{ }^{\circ} \mathrm{C}\right)$ [19].

6-Methyl-4-(4-methylphenyl)-3,4-dihydropyrimidine-2(1H)-thione $\left(2 \mathrm{c}, \mathrm{C}_{12} \mathrm{H}_{14} \mathrm{~N}_{2} \mathrm{~S}\right)$ The reaction of $21.27 \mathrm{~g}$ of $1 \mathrm{c}(132.76 \mathrm{mmol})$ with $8.26 \mathrm{~g}$ of ammonium thiocyanate ( $108.5 \mathrm{mmol})$ was carried out in $400 \mathrm{~cm}^{3}$ of toluene in the presence of $4.12 \mathrm{~g}$ of cyclohexanol $(41.16 \mathrm{mmol})$. The mixture was heated for $18 \mathrm{~h}$ at $160{ }^{\circ} \mathrm{C}$ oil bath temperature using a water separator filled with molecular sieves $4 \AA$ A . After cooling to r.t., the orange precipitate was collected by filtration, washed with ether and ethanol. Then it was dissolved in a mixture of hot ethanol/isopropanol (3:1), treated with charcoal and filtered. The filtrate was concentrated in vacuo. Thereafter it was allowed to stand overnight at r.t. to complete crystallization. The product was collected by filtration, washed with ethanol, and dried. Yield: $11.85 \mathrm{~g}$ of $\mathbf{2 c}(41 \%)$ as white crystals. $R_{\mathrm{f}}=0.84$ (benzene: $\mathrm{CHCl}_{3}: \mathrm{EtOH}=4: 4: 1$ ); m.p.: $207{ }^{\circ} \mathrm{C} ;{ }^{1} \mathrm{H}$ NMR (DMSO- $d_{6}, 400 \mathrm{MHz}$ ): $\delta=1.69$ (s, $\left.3 \mathrm{H}, \mathrm{CH}_{3}\right), 2.26\left(\mathrm{~s}, 3 \mathrm{H}, \mathrm{ArCH}_{3}\right), 4.68(\mathrm{~d}, J=1.8 \mathrm{~Hz}, 1 \mathrm{H}$, H-5), 4.85 (s, 1H, H-4), 7.10 (d, J=8.1 Hz, 2H, ArH), 7.15 (d, J=7.7 Hz, 2H, ArH), 8.76 (s, 1H, H-3), 9.52 (s, 1H, H-1) 
ppm; ${ }^{13} \mathrm{C}$ NMR (DMSO- $\left.d_{6}, 100 \mathrm{MHz}\right): \delta=17.87\left(\mathrm{CH}_{3}\right)$, $20.90\left(\mathrm{ArCH}_{3}\right), 54.75(\mathrm{C}-4), 99.49$ (C-5), 126.43, 129.24 (ArC), 130.78 (C-6), 136.73, $142.05\left(\mathrm{ArC}_{\mathrm{q}}\right), 174.18$ (C-2) ppm; IR (KBr): $\bar{v}=3184,2987,1706,1569,1489,1323$, 1197, 1180, 844, 819, $790 \mathrm{~cm}^{-1}$; HRMS (EI+): $\mathrm{m} / z$ calcd $\mathrm{C}_{12} \mathrm{H}_{14} \mathrm{~N}_{2} \mathrm{~S}\left[\mathrm{M}^{+}\right]$218.0878, found 218.0874.

\section{Preparation of pyrimidine-2-thiols 3b-3d}

The aromatization of dihydropyrimidine-2(1H)-thiones $\mathbf{2 b}, \mathbf{2 c}$, and $\mathbf{2 d}$ took place overnight in refluxing xylene in the presence of sulfur. The solution was then allowed to cool to r.t.. A precipitate was formed which was collected by filtration. The solid was stirred with $1 \mathrm{~N} \mathrm{NaOH}$ and filtered. The filtrate was acidified with $2 \mathrm{~N} \mathrm{HCl}$. The precipitate was collected by filtration, washed with water and recrystallized.

4-(4-Chlorophenyl)-6-methylpyrimidine-2-thiol (3b, $\left.\mathrm{C}_{11} \mathrm{H}_{9} \mathrm{CIN}_{2} \mathrm{~S}\right)$ Reaction of $3.99 \mathrm{~g}$ of $2 \mathrm{~b}(16.7 \mathrm{mmol})$ with $3.2 \mathrm{~g}$ of sulfur $(0.1 \mathrm{~mol})$ in $24 \mathrm{~cm}^{3}$ of xylene yielded after crystallization from a mixture of ethanol and propan-2-ol $1.75 \mathrm{~g}$ of $\mathbf{3 b}(44 \%)$ as orange powder. $R_{\mathrm{f}}=0.58$ $\left(\mathrm{CH}_{2} \mathrm{Cl}_{2}: \mathrm{CH}_{3} \mathrm{OH}=10: 1\right)$; m.p.: $249{ }^{\circ} \mathrm{C} ;{ }^{1} \mathrm{H}$ NMR (DMSO$\left.d_{6}, 400 \mathrm{MHz}\right): \delta=2.34$ (s, $\left.3 \mathrm{H}, \mathrm{CH}_{3}\right), 7.37$ (s, $\left.1 \mathrm{H}, \mathrm{H}-5\right)$, $7.59(\mathrm{~d}, J=8.7 \mathrm{~Hz}, 2 \mathrm{H}, \mathrm{ArH}), 8.13(\mathrm{~d}, J=8.6 \mathrm{~Hz}, 2 \mathrm{H}$, ArH), 13.72 (br, s, 1H, SH) ppm; ${ }^{13} \mathrm{C}$ NMR (DMSO- $d_{6}$, $100 \mathrm{MHz}): \delta=18.82\left(\mathrm{CH}_{3}\right), 106.08(\mathrm{C}-5), 129.23,129.84$ (ArC), 134.31, $137.25\left(\mathrm{ArC}_{\mathrm{q}}\right), 159.37$ (C-6), 164.36 (C-4), 181.34 (C-2) ppm; IR (KBr): $\bar{v}=3441,2920,2360,1611$, 1577, 1552, 1457, 1280, 1230, 1169, 1090, 977, $809 \mathrm{~cm}^{-1}$; HRMS (EI+): $m / z$ calcd. $\left(\mathrm{C}_{11} \mathrm{H}_{9} \mathrm{ClN}_{2} \mathrm{~S}\right)\left[\mathrm{M}^{+}\right]$236.0175, found 236.0162 .

4-Methyl-6-(4-methylphenyl)pyrimidine-2-thiol (3c, $\left.\mathrm{C}_{12} \mathrm{H}_{12} \mathrm{~N}_{2} \mathrm{~S}\right)$ Reaction of $11.85 \mathrm{~g}$ of $2 \mathrm{c}(54.28 \mathrm{mmol})$ with $2.09 \mathrm{~g}$ of sulfur $(65.2 \mathrm{mmol})$ in $80 \mathrm{~cm}^{3}$ of xylene yielded after crystallization from ethanol $4.35 \mathrm{~g}$ of $\mathbf{3 c}(37 \%)$ as yellow powder. $R_{\mathrm{f}}=0.57\left(\mathrm{CH}_{2} \mathrm{Cl}_{2}: \mathrm{CH}_{3} \mathrm{OH}=10: 1\right)$; m.p.: $249{ }^{\circ} \mathrm{C} ;{ }^{1} \mathrm{H}$ NMR (DMSO- $d_{6}, 400 \mathrm{MHz}$ ): $\delta=2.33$ (s, $3 \mathrm{H}$, $\mathrm{CH}_{3}$ ), 2.36 (s, 3H, $\mathrm{ArCH}_{3}$ ), 7.32-7.34 (m, 3H, H-5, ArH), $8.03(\mathrm{~d}, J=8.1 \mathrm{~Hz}, 2 \mathrm{H}, \mathrm{ArH}), 13.60$ (br, s, 1H, SH) ppm; ${ }^{13} \mathrm{C}$ NMR (DMSO- $\left.d_{6}, 100 \mathrm{MHz}\right): \delta=18.75\left(\mathrm{CH}_{3}\right), 21.26$ $\left(\mathrm{ArCH}_{3}\right), 105.78(\mathrm{C}-5), 128.05,129.74(\mathrm{ArC}), 132.69$, $142.58\left(\mathrm{ArC}_{\mathrm{q}}\right), 158.67$ (C-4), 165.39 (C-6), 181.27 (C-2) ppm; IR (KBr): $\bar{v}=2827,1612,1577,1553,1453,1336$, 1288, 1238, 1198, 1173, 976, $811 \mathrm{~cm}^{-1}$; HRMS (EI +): $\mathrm{m} / \mathrm{z}$ calcd. $\left(\mathrm{C}_{12} \mathrm{H}_{12} \mathrm{~N}_{2} \mathrm{~S}\right)\left[\mathrm{M}^{+}\right]$216.0721, found 216.0712.

4-(4-Methoxyphenyl)-6-methylpyrimidine-2-thiol (3d, $\left.\mathrm{C}_{12} \mathrm{H}_{12} \mathrm{~N}_{2} \mathrm{OS}\right)$ Reaction of $6.29 \mathrm{~g}$ of $2 \mathrm{~d}(26.86 \mathrm{mmol})$ with $1.03 \mathrm{~g}$ of sulfur $(32.23 \mathrm{mmol})$ in $40 \mathrm{~cm}^{3}$ of xylene yielded after crystallization with ethanol $2.02 \mathrm{~g}$ of $\mathbf{3 d}(32 \%)$ as buff powder. $R_{\mathrm{f}}=0.48\left(\mathrm{CH}_{2} \mathrm{Cl}_{2}: \mathrm{CH}_{3} \mathrm{OH}=10: 1\right)$; m.p.: $243-$ $245^{\circ} \mathrm{C} ;{ }^{1} \mathrm{H}$ NMR (DMSO- $d_{6}, 400 \mathrm{MHz}$ ): $\delta=2.32$ (s, $3 \mathrm{H}$, $\mathrm{CH}_{3}$ ), 3.83 (s, $\left.3 \mathrm{H}, \mathrm{OCH}_{3}\right), 7.06$ (d, $\left.J=8.8 \mathrm{~Hz}, 2 \mathrm{H}, \mathrm{ArH}\right)$, 7.30 (s, 1H, H-5), 8.11 (d, J=8.8 Hz, 2H, ArH), 13.50 (br, $\mathrm{s}, 1 \mathrm{H}, \mathrm{SH}) \mathrm{ppm} ;{ }^{13} \mathrm{C}$ NMR (DMSO- $d_{6}, 100 \mathrm{MHz}$ ): $\delta=18.71$ $\left(\mathrm{CH}_{3}\right), 55.69\left(\mathrm{OCH}_{3}\right), 105.26(\mathrm{C}-5), 114.53(\mathrm{ArC}), 127.62$ $\left(\mathrm{ArC}_{\mathrm{q}}\right), 130.03(\mathrm{ArC}), 158.22(\mathrm{C}-6), 162.81\left(\mathrm{ArC}_{\mathrm{q}}\right), 164.92$ (C-4), 181.09 (C-2) ppm; IR (KBr): $\bar{v}=2836,1619,1605$, 1581, 1553, 1456, 1340, 1257, 1242, 1203, 1168, 1027, 976, $818 \mathrm{~cm}^{-1}$; HRMS (EI + ): $\mathrm{m} / z$ calcd. $\left(\mathrm{C}_{12} \mathrm{H}_{12} \mathrm{~N}_{2} \mathrm{OS}\right)\left[\mathrm{M}^{+}\right]$ 232.0670, found 232.0655 .

\section{Preparation of (methylsulfanyl)pyrimidine hydroiodides $\mathbf{4 b - 4 d}$}

To a stirred suspension of $\mathbf{3 b}, \mathbf{3 c}$, or $\mathbf{3 d}$ in $\mathrm{CHCl}_{3}$ methyliodide $\left(\mathrm{CH}_{3} \mathrm{I}\right)$ was added dropwise. Stirring was continued at r.t. for up to 3 days. Then the formed solid was collected by filtration. The filtrate was evaporated to dryness and the residue was crystallized by treatment with ethyl acetate to give a second portion of the product. The solids were combined and dried.

4-(4-Chlorophenyl)-6-methyl-2-(methylsulfanyl)pyrimidine hydroiodide $\left(4 \mathrm{~b}, \mathrm{C}_{12} \mathrm{H}_{12} \mathrm{CIIN}_{2} \mathrm{~S}\right)$ Reaction of $1.65 \mathrm{~g}$ of $3 \mathbf{b}(6.9 \mathrm{mmol})$ in $50 \mathrm{~cm}^{3}$ of $\mathrm{CHCl}_{3}$ with $2.48 \mathrm{~g}$ of $\mathrm{CH}_{3} \mathrm{I}$ (17.4 mmol) yielded overnight $1.948 \mathrm{~g}$ of $\mathbf{4 b}(75 \%)$ as yellow-orange precipitate. $R_{\mathrm{f}}=0.60\left(\mathrm{CH}_{2} \mathrm{Cl}_{2}: \mathrm{CH}_{3} \mathrm{OH}=10: 1\right)$; m.p.: $193{ }^{\circ} \mathrm{C} ;{ }^{1} \mathrm{H}$ NMR (DMSO- $d_{6}, 400 \mathrm{MHz}$ ): $\delta=2.46$ $\left(\mathrm{s}, 3 \mathrm{H}, \mathrm{CH}_{3}\right), 2.57\left(\mathrm{~s}, 3 \mathrm{H}, \mathrm{SCH}_{3}\right), 7.60(\mathrm{~d}, J=8.6 \mathrm{~Hz}, 2 \mathrm{H}$, ArH), 7.70 (s, 1H, H-5), 8.20 (d, $J=8.6 \mathrm{~Hz}, 2 \mathrm{H}, \mathrm{ArH})$ ppm; ${ }^{13} \mathrm{C}$ NMR (DMSO- $\left.d_{6}, 100 \mathrm{MHz}\right): \delta=13.81\left(\mathrm{SCH}_{3}\right)$, $23.96\left(\mathrm{CH}_{3}\right), 112.00$ (C-5), 129.04, 129.29 (ArC), 134.85, $136.32\left(\mathrm{ArC}_{\mathrm{q}}\right), 161.71(\mathrm{C}-4), 168.66$ (C-6), 171.25 (C-2) ppm; IR (KBr): $\bar{v}=2862,1610,1577,1552,1455,1335$, 1279, 1229, 1168, 1089, 1010, 977, 818, $808 \mathrm{~cm}^{-1}$; HRMS $(\mathrm{EI}+): \mathrm{m} / z$ calcd. $\left(\mathrm{C}_{11} \mathrm{H}_{8} \mathrm{ClN}_{2} \mathrm{~S}\right)\left[\mathrm{M}^{+}-\mathrm{H}-\mathrm{CH}_{3} \mathrm{I}\right] 235.0097$, found 235.0092 .

4-Methyl-6-(4-methylphenyl)-2-(methylsulfanyl)pyrimidine hydroiodide (4c, $\mathrm{C}_{13} \mathrm{H}_{15} \mathrm{IN}_{2} \mathrm{~S}$ ) Reaction of $4.21 \mathrm{~g}$ of $3 \mathrm{c}$ (19.46 mmol) in $250 \mathrm{~cm}^{3}$ of $\mathrm{CHCl}_{3}$ with $6.63 \mathrm{~g}$ of $\mathrm{CH}_{3} \mathrm{I}$ (46.71 mmol) yielded after 3 days $5.73 \mathrm{~g}$ of $\mathbf{4 c}(82 \%)$ as brown solid. $R_{\mathrm{f}}=0.81\left(\mathrm{CH}_{2} \mathrm{Cl}_{2}: \mathrm{MeOH}=10: 1\right)$; m.p.: 208 $209{ }^{\circ} \mathrm{C} ;{ }^{1} \mathrm{H}$ NMR (DMSO- $d_{6}, 400 \mathrm{MHz}$ ): $\delta=2.34$ (s, 3H, $\left.\mathrm{ArCH}_{3}\right), 2.43$ (s, 3H, $\left.\mathrm{CH}_{3}\right), 2.56\left(\mathrm{~s}, 3 \mathrm{H}, \mathrm{SCH}_{3}\right), 7.31$ (d, $J=8.1 \mathrm{~Hz}, 2 \mathrm{H}, \mathrm{ArH}), 7.66$ (s, $1 \mathrm{H}, \mathrm{H}-5), 8.06(\mathrm{~d}, J=8.1 \mathrm{~Hz}$, $2 \mathrm{H}, \mathrm{ArH}$ ) ppm; ${ }^{13} \mathrm{C}$ NMR (DMSO- $d_{6}, 100 \mathrm{MHz}$ ): $\delta=13.79$ $\left(\mathrm{SCH}_{3}\right), 21.27\left(\mathrm{ArCH}_{3}\right), 23.55\left(\mathrm{CH}_{3}\right), 111.68(\mathrm{C}-5), 127.31$, 129.82 (ArC), 132.99, $141.77\left(\mathrm{ArC}_{\mathrm{q}}\right), 163.21$ (C-6), 167.73 (C-4), 170.49 (C-2) ppm; IR (KBr): $\bar{v}=2732,1620,1578$, 
1429, 1349, 1298, 1273, 1206, 1190, $834 \mathrm{~cm}^{-1}$; HRMS $(\mathrm{EI}+): \mathrm{m} / z$ calcd. $\left(\mathrm{C}_{13} \mathrm{H}_{14} \mathrm{~N}_{2} \mathrm{~S}\right)\left[\mathrm{M}^{+}-\mathrm{HI}\right] 230.0878$, found 230.0877 .

4-(4-Methoxyphenyl)-6-methyl-2-(methylsulfanyl)pyrimidine hydroiodide (4d, $\mathrm{C}_{13} \mathrm{H}_{15} \mathrm{IN}_{2} \mathrm{OS}$ ) Reaction of $1.88 \mathrm{~g}$ of $\mathbf{4 d}$ (8.1 mmol) in $120 \mathrm{~cm}^{3}$ of $\mathrm{CHCl}_{3}$ with $2.75 \mathrm{~g}$ of $\mathrm{CH}_{3} \mathrm{I}$ yielded after 2 days $2.65 \mathrm{~g}$ of $\mathbf{4 d}(87 \%)$ as yellow solid. $R_{\mathrm{f}}=0.76$ $\left(\mathrm{CH}_{2} \mathrm{Cl}_{2}: \mathrm{MeOH}=10: 1\right)$; m.p.: $213{ }^{\circ} \mathrm{C} ;{ }^{1} \mathrm{H}$ NMR (DMSO$\left.d_{6}, 400 \mathrm{MHz}\right): \delta=2.43\left(\mathrm{~s}, 3 \mathrm{H}, \mathrm{CH}_{3}\right), 2.57\left(\mathrm{~s}, 3 \mathrm{H}, \mathrm{SCH}_{3}\right.$ ), $3.81\left(\mathrm{~s}, 3 \mathrm{H}, \mathrm{OCH}_{3}\right), 7.05(\mathrm{~d}, J=8.8 \mathrm{~Hz}, 2 \mathrm{H}, \mathrm{ArH}), 7.66(\mathrm{~s}$, $1 \mathrm{H}, \mathrm{H}-5), 8.15(\mathrm{~d}, J=8.8 \mathrm{~Hz}, 2 \mathrm{H}, \mathrm{ArH}) \mathrm{ppm} ;{ }^{13} \mathrm{C} \mathrm{NMR}$ $\left(\right.$ DMSO- $\left.d_{6}, 100 \mathrm{MHz}\right): \delta=13.79\left(\mathrm{SCH}_{3}\right), 23.17\left(\mathrm{CH}_{3}\right)$, $55.75\left(\mathrm{OCH}_{3}\right), 111.19(\mathrm{C}-5), 114.66(\mathrm{ArC}), 127.78\left(\mathrm{ArC}_{\mathrm{q}}\right)$, $129.33(\mathrm{ArC}), 162.45\left(\mathrm{ArC}_{\mathrm{q}}\right), 163.21(\mathrm{C}-4), 166.90(\mathrm{C}-6)$, 169.85 (C-2) ppm; IR (KBr): $\bar{v}=2698,1602,1560,1399$, $1348,1262,1212,1178,1022,834 \mathrm{~cm}^{-1}$; HRMS (EI+): $\mathrm{m} / \mathrm{z}$ calcd. $\left(\mathrm{C}_{13} \mathrm{H}_{14} \mathrm{~N}_{2} \mathrm{OS}\right)\left[\mathrm{M}^{+}-\mathrm{HI}\right] 246.0827$, found 246.0812 .

\section{Preparation of (methanesulfonyl) pyrimidines $\mathbf{5 a - 5 d}$}

The methylthio-pyrimidine hydroiodides $4 \mathbf{a}, \mathbf{4 b}, \mathbf{4 c}$, or $\mathbf{4 d}$ were dissolved in $\mathrm{CH}_{2} \mathrm{Cl}_{2}$. The resulting solution was cooled down to $0{ }^{\circ} \mathrm{C}$ and 3-chloroperoxybenzoic acid (77\%) was added slowly with stirring and cooling. The color of the solution turned to cerise, the ice bath was removed and the reaction mixture was stirred for $2 \mathrm{~h}$ at r.t.. During the reaction the color of the solution turned to violet due to the oxidation of iodide to iodine. The organic layer was washed once with saturated $\mathrm{NaHCO}_{3}$ solution, once with an aqueous $\mathrm{Na}_{2} \mathrm{~S}_{2} \mathrm{O}_{3}$ solution, and finally with brine. Then it was dried over anhydrous $\mathrm{Na}_{2} \mathrm{SO}_{4}$ and filtered. The solvent was evaporated in vacuo giving white solids which were recrystallized with a small amount of ethyl acetate giving colorless needles.

2-(Methanesulfonyl)-4-methyl-6-phenylpyrimidine (5a, $\left.\mathrm{C}_{12} \mathrm{H}_{12} \mathrm{~N}_{2} \mathrm{O}_{2} \mathrm{~S}\right)$ Reaction of $1.124 \mathrm{~g}$ of $4 \mathrm{a}(3.27 \mathrm{mmol})$ in $120 \mathrm{~cm}^{3}$ of $\mathrm{CH}_{2} \mathrm{Cl}_{2}$ with $2.452 \mathrm{~g}$ of 3-chloroperoxybenzoic acid $(10.94 \mathrm{mmol})$ yielded $751 \mathrm{mg}$ of $\mathbf{5 a}(92 \%) . R_{\mathrm{f}}=0.75$ $\left(\mathrm{CH}_{2} \mathrm{Cl}_{2}: \mathrm{CH}_{3} \mathrm{OH}=10: 1\right)$; m.p.: $176{ }^{\circ} \mathrm{C} ;{ }^{1} \mathrm{H} \mathrm{NMR}\left(\mathrm{CDCl}_{3}\right.$, $400 \mathrm{MHz}): \delta=2.73\left(\mathrm{~s}, 3 \mathrm{H}, \mathrm{CH}_{3}\right), 3.44\left(\mathrm{~s}, 3 \mathrm{H}, \mathrm{SO}_{2} \mathrm{CH}_{3}\right)$, 7.52-7.58 (m, 3H, ArH), $7.75(\mathrm{~s}, 1 \mathrm{H}, \mathrm{H}-5), 8.14(\mathrm{~d}$, $J=6.6 \mathrm{~Hz}, 2 \mathrm{H}, \mathrm{ArH}) \mathrm{ppm} ;{ }^{13} \mathrm{C} \mathrm{NMR}\left(\mathrm{CDCl}_{3}, 100 \mathrm{MHz}\right)$ : $\delta=24.38\left(\mathrm{CH}_{3}\right), 39.01\left(\mathrm{SO}_{2} \mathrm{CH}_{3}\right), 118.31(\mathrm{C}-5), 127.41$, $129.09,132.01$ (ArC), $134.63\left(\mathrm{ArC}_{\mathrm{q}}\right), 165.18(\mathrm{C}-6)$, 165.90 (C-2), 170.36 (C-4) ppm; IR (KBr): $\bar{v}=3015,1590$, 1515, 1499, 1426, 1353, 1296, 1223, 1141, 974, 965, 883, 793, 765, 751, $697 \mathrm{~cm}^{-1}$; HRMS (EI +): $\mathrm{m} / \mathrm{z}$ calcd. $\left(\mathrm{C}_{12} \mathrm{H}_{12} \mathrm{~N}_{2} \mathrm{O}_{2} \mathrm{~S}\right)\left[\mathrm{M}^{+}\right] 248.0620$, found 248.0623.
4-(4-Chlorophenyl)-2-(methanesulfonyl)-6-methylpyrimidine $\left(5 \mathrm{~b}, \mathrm{C}_{12} \mathrm{H}_{11} \mathrm{CIN}_{2} \mathrm{O}_{2} \mathrm{~S}\right)$ Reaction of $378 \mathrm{mg}$ of $4 \mathrm{~b}$ (1.00 mmol) in $36 \mathrm{~cm}^{3}$ of $\mathrm{CH}_{2} \mathrm{Cl}_{2}$ with $1 \mathrm{~g}$ of 3-chloroperoxybenzoic acid $(4.46 \mathrm{mmol})$ yielded $246 \mathrm{mg}$ of $\mathbf{5 b}$ (87\%). $R_{\mathrm{f}}=0.75\left(\mathrm{CH}_{2} \mathrm{Cl}_{2}: \mathrm{CH}_{3} \mathrm{OH}=10: 1\right) ;$ m.p.: $=161{ }^{\circ} \mathrm{C}$; ${ }^{1} \mathrm{H}$ NMR $\left(\mathrm{CDCl}_{3}, 400 \mathrm{MHz}\right): \delta=2.71\left(\mathrm{~s}, 3 \mathrm{H}, \mathrm{CH}_{3}\right), 3.42$ (s, 3H, $\left.\mathrm{SO}_{2} \mathrm{CH}_{3}\right), 7.49$ (d, J=8.6 Hz, 2H, $\left.\mathrm{ArH}\right), 7.73(\mathrm{~s}, 1 \mathrm{H}$, $\mathrm{H}-5), 8.08(\mathrm{~d}, J=8.6 \mathrm{~Hz}, 2 \mathrm{H}, \mathrm{ArH}) \mathrm{ppm} ;{ }^{13} \mathrm{C} \mathrm{NMR}\left(\mathrm{CDCl}_{3}\right.$, $100 \mathrm{MHz}): \delta=24.41\left(\mathrm{CH}_{3}\right), 39.02\left(\mathrm{SO}_{2} \mathrm{CH}_{3}\right), 118.12(\mathrm{C}-5)$, 128.72, $129.39(\mathrm{ArC}), 133.06,138.42\left(\mathrm{ArC}_{\mathrm{q}}\right), 164.02(\mathrm{C}-4)$, 165.94 (C-2), 170.61 (C-6) ppm; IR (KBr): $\bar{v}=3013,1591$, $1575,1513,1494,1444,1398,1356,1324,1301,1228$, 1137, 1094, 1012, 968, 840, $754 \mathrm{~cm}^{-1}$; HRMS (EI +): $\mathrm{m} / \mathrm{z}$ calcd. $\left(\mathrm{C}_{12} \mathrm{H}_{11} \mathrm{ClN}_{2} \mathrm{O}_{2} \mathrm{~S}\right)\left[\mathrm{M}^{+}\right]$282.0230, found 282.0224.

2-(Methanesulfonyl)-4-methyl-6-(4-methylphenyl)pyrimidine $\left(5 \mathrm{c}, \mathrm{C}_{13} \mathrm{H}_{14} \mathrm{~N}_{2} \mathrm{O}_{2} \mathrm{~S}\right.$ ) Reaction of $5.61 \mathrm{~g}$ of $4 \mathrm{c}$ (15.66 mmol) in $575 \mathrm{~cm}^{3}$ of $\mathrm{CH}_{2} \mathrm{Cl}_{2}$ with $11.77 \mathrm{~g}$ of 3-chloroperoxybenzoic acid $(52.52 \mathrm{mmol})$ yielded $2.996 \mathrm{~g}$ of $\mathbf{5 c}$ (73\%). $R_{\mathrm{f}}=0.44$ (cyclohexane: ethyl acetate $=1: 3$ ); m.p.: $146-147^{\circ} \mathrm{C} ;{ }^{1} \mathrm{H}$ NMR $\left(\mathrm{CDCl}_{3}, 400 \mathrm{MHz}\right): \delta=2.43$ (s, 3H, $\left.\mathrm{ArCH}_{3}\right), 2.69$ (s, $\left.3 \mathrm{H}, \mathrm{CH}_{3}\right), 3.42\left(\mathrm{~s}, 3 \mathrm{H}, \mathrm{SO}_{2} \mathrm{CH}_{3}\right), 7.32$ (d, $J=8.1 \mathrm{~Hz}, 2 \mathrm{H}, \mathrm{ArH}), 7.71$ (s, $1 \mathrm{H}, \mathrm{H}-5), 8.03$ (d, $J=8.1 \mathrm{~Hz}$, $2 \mathrm{H}, \mathrm{ArH}) \mathrm{ppm} ;{ }^{13} \mathrm{C} \mathrm{NMR}\left(\mathrm{CDCl}_{3}, 100 \mathrm{MHz}\right): \delta=21.46$ $\left(\mathrm{ArCH}_{3}\right), 24.34\left(\mathrm{CH}_{3}\right), 38.99\left(\mathrm{SO}_{2} \mathrm{CH}_{3}\right), 117.84(\mathrm{C}-5)$, 127.34, $129.82(\mathrm{ArC}), 131.83,142.75\left(\mathrm{ArC}_{\mathrm{q}}\right), 165.11(\mathrm{C}-6)$, 165.82 (C-2), 170.08 (C-4) ppm; IR (KBr): $\bar{v}=3013,1587$, 1521, 1504, 1444, 1355, 1304, 1138, 966, 828, $746 \mathrm{~cm}^{-1}$; HRMS (EI+): $m / z$ calcd. $\left(\mathrm{C}_{13} \mathrm{H}_{14} \mathrm{~N}_{2} \mathrm{O}_{2} \mathrm{~S}\right)\left[\mathrm{M}^{+}\right] 262.0776$, found 262.0766 .

2-(Methanesulfonyl)-4-(4-methoxyphenyl)-6-methylpyrimidine $\left(5 \mathrm{~d}, \mathrm{C}_{13} \mathrm{H}_{14} \mathrm{~N}_{2} \mathrm{O}_{3} \mathrm{~S}\right)$ Reaction of $2.512 \mathrm{~g}$ of $4 \mathrm{~d}$ (6.72 mmol) in $250 \mathrm{~cm}^{3}$ of $\mathrm{CH}_{2} \mathrm{Cl}_{2}$ with $5.04 \mathrm{~g}$ of 3-chloroperoxybenzoic acid $(22.49 \mathrm{mmol})$ yielded $1.32 \mathrm{~g}$ of $\mathbf{5 d}(71 \%)$. $R_{\mathrm{f}}=0.75\left(\mathrm{CH}_{2} \mathrm{Cl}_{2}: \mathrm{CH}_{3} \mathrm{OH}=10: 1\right) ;$ m.p.: $135-136{ }^{\circ} \mathrm{C} ;{ }^{1} \mathrm{H}$ NMR ( $\left.\mathrm{CDCl}_{3}, 400 \mathrm{MHz}\right): \delta=2.66\left(\mathrm{~s}, 3 \mathrm{H}, \mathrm{CH}_{3}\right), 3.41(\mathrm{~s}, 3 \mathrm{H}$, $\left.\mathrm{SO}_{2} \mathrm{CH}_{3}\right), 3.88\left(\mathrm{~s}, 3 \mathrm{H}, \mathrm{OCH}_{3}\right), 7.00(\mathrm{~d}, J=8.8 \mathrm{~Hz}, 2 \mathrm{H}, \mathrm{ArH})$, 7.65 (s, $1 \mathrm{H}, \mathrm{H}-5), 8.10(\mathrm{~d}, J=8.8 \mathrm{~Hz}, 2 \mathrm{H}, \mathrm{ArH}) \mathrm{ppm} ;{ }^{13} \mathrm{C}$ NMR ( $\left(\mathrm{CDCl}_{3}, 100 \mathrm{MHz}\right): \delta=24.29\left(\mathrm{CH}_{3}\right), 38.96\left(\mathrm{SO}_{2} \mathrm{CH}_{3}\right)$, $55.42\left(\mathrm{OCH}_{3}\right), 114.40(\mathrm{ArC}), 117.14(\mathrm{C}-5), 126.89\left(\mathrm{ArC}_{\mathrm{q}}\right)$, $129.12(\mathrm{ArC}), 162.82\left(\mathrm{ArC}_{\mathrm{q}}\right), 164.61(\mathrm{C}-4), 165.72(\mathrm{C}-2)$, 169.75 (C-6) ppm; IR (KBr): $\bar{v}=2932,1587,1524,1417$, 1354, 1298, 1281, 1261, 1223, 1189, 1140, 1021, 840, $750 \mathrm{~cm}^{-1}$; HRMS (EI+): $\mathrm{m} / z$ calcd. $\left(\mathrm{C}_{13} \mathrm{H}_{14} \mathrm{~N}_{2} \mathrm{O}_{3} \mathrm{~S}\right)\left[\mathrm{M}^{+}\right]$ 278.0725 , found 278.0727 .

\section{Preparation of pyrimidin-2-amines $6 a-6 d$}

The pyrimidin-2-amines were prepared similar to a reported procedure [20]. Compounds $\mathbf{5 a}, \mathbf{5 b}, \mathbf{5 c}$, or $\mathbf{5 d}$ were suspended in dioxane and concentrated aqueous $\mathrm{NH}_{3}$ was 
added. The reaction mixture was subjected to microwave irradiation at $120^{\circ} \mathrm{C}$. The solvents were evaporated in vacuo to dryness. Water was added and the mixture was extracted 5 times with $\mathrm{CH}_{2} \mathrm{Cl}_{2}$. The combined organic layers were washed once with water, dried over anhydrous $\mathrm{Na}_{2} \mathrm{SO}_{4}$, and filtered. The solvent was evaporated in vacuo giving a crystalline residue. The crude products were purified by means of sublimation at reduced pressure yielding the products as white needles.

4-Methyl-6-phenylpyrimidin-2-amine $\left(6 \mathrm{a}, \mathrm{C}_{11} \mathrm{H}_{11} \mathrm{~N}_{3}\right)$ Reaction of $200 \mathrm{mg}$ of $\mathbf{5 a}(0.81 \mathrm{mmol})$ with $1.34 \mathrm{~cm}^{3}$ of concentrated aqueous $\mathrm{NH}_{3}(18 \mathrm{mmol})$ in $4.8 \mathrm{~cm}^{3}$ of dioxane for $2 \mathrm{~h}$ yielded $66 \mathrm{mg}$ of $\mathbf{6 a}(44 \%)$. The melting point $\left(169-170{ }^{\circ} \mathrm{C}\right)$ corresponded well with the reported one $\left(169-171^{\circ} \mathrm{C}\right)$ [21]. $R_{\mathrm{f}}=0.63\left(\mathrm{CH}_{2} \mathrm{Cl}_{2}: \mathrm{CH}_{3} \mathrm{OH}=9: 1\right) ;{ }^{1} \mathrm{H}$ NMR (DMSO- $d_{6}$, $400 \mathrm{MHz}): \delta=2.29\left(\mathrm{~s}, 3 \mathrm{H}, \mathrm{CH}_{3}\right), 6.58\left(\mathrm{~s}, 2 \mathrm{H}, \mathrm{NH}_{2}\right), 7.02(\mathrm{~s}$, 1H, H-5), 7.45-7.47 (m, 3H, ArH), 8.02-8.05 (m, 2H, ArH) ppm; ${ }^{13} \mathrm{C}$ NMR (DMSO- $\left.d_{6}, 100 \mathrm{MHz}\right): \delta=23.91\left(\mathrm{CH}_{3}\right)$, $105.38(\mathrm{C}-5), 126.86,128.80,130.43(\mathrm{ArC}), 137.46\left(\mathrm{ArC}_{\mathrm{q}}\right)$, 163.75 (C-6), 163.90 (C-2), 168.39 (C-4) ppm; IR (KBr): $\bar{v}=3323,3194,1637,1601,1579,1551,1464,1380,1353$, $1227,770,708 \mathrm{~cm}^{-1}$; HRMS (EI+): $\mathrm{m} / z$ calcd. $\left(\mathrm{C}_{11} \mathrm{H}_{11} \mathrm{~N}_{3}\right)$ $\left[\mathrm{M}^{+}\right]$185.0953, found 185.0942.

4-(4-Chlorophenyl)-6-methylpyrimidin-2-amine (6b, $\left.\mathrm{C}_{11} \mathrm{H}_{10} \mathrm{CIN}_{3}\right)$ Reaction of $215 \mathrm{mg}$ of $\mathbf{5 b}(0.76 \mathrm{mmol})$ with $1.27 \mathrm{~cm}^{3}$ of concentrated aqueous $\mathrm{NH}_{3}(17 \mathrm{mmol})$ in $4.6 \mathrm{~cm}^{3}$ of dioxane for $3 \mathrm{~h}$ yielded $50 \mathrm{mg}$ of $\mathbf{6} \mathbf{b}(30 \%)$. The melting point $\left(198^{\circ} \mathrm{C}\right)$ was similar to the reported one $\left(204^{\circ} \mathrm{C}\right)$ [22]. $R_{\mathrm{f}}=0.47\left(\mathrm{CH}_{2} \mathrm{Cl}_{2}: \mathrm{CH}_{3} \mathrm{OH}=20: 1\right) ;{ }^{1} \mathrm{H}$ NMR (DMSO- $d_{6}$, $400 \mathrm{MHz}): \delta=2.28\left(\mathrm{~s}, 3 \mathrm{H}, \mathrm{CH}_{3}\right), 6.62\left(\mathrm{~s}, 2 \mathrm{H}, \mathrm{NH}_{2}\right), 7.03(\mathrm{~s}$, $1 \mathrm{H}, \mathrm{H}-5), 7.52(\mathrm{~d}, J=8.4 \mathrm{~Hz}, 2 \mathrm{H}, \mathrm{ArH}), 8.05(\mathrm{~d}, J=8.8 \mathrm{~Hz}$, $2 \mathrm{H}, \mathrm{ArH}$ ) ppm; ${ }^{13} \mathrm{C}$ NMR (DMSO- $\left.d_{6}, 100 \mathrm{MHz}\right): \delta=23.91$ $\left(\mathrm{CH}_{3}\right), 105.27$ (C-5), 128.62, $128.86(\mathrm{ArC}), 135.19,136.26$ $\left(\mathrm{ArC}_{\mathrm{q}}\right), 162.42$ (C-4), 163.86 (C-2), 168.68 (C-6) ppm; IR (KBr): $\bar{v}=3306,3162,1639,1595,1572,1551,1492,1463$, $1089,808 \mathrm{~cm}^{-1}$; HRMS (EI+): $\mathrm{m} / z$ calcd. $\left(\mathrm{C}_{11} \mathrm{H}_{10} \mathrm{ClN}_{3}\right)$ $\left[\mathrm{M}^{+}\right]$219.0563, found 219.0553 .

4-Methyl-6-(4-methylphenyl)pyrimidin-2-amine (6c, $\left.\mathrm{C}_{12} \mathrm{H}_{13} \mathrm{~N}_{3}\right)$ Reaction of $200 \mathrm{mg}$ of $\mathbf{5 c}(0.76 \mathrm{mmol})$ with 1.27 $\mathrm{cm}^{3}(16.70 \mathrm{mmol})$ of concentrated aqueous $\mathrm{NH}_{3}$ in $4.6 \mathrm{~cm}^{3}$ of dioxane for $3 \mathrm{~h}$ yielded $100 \mathrm{mg}$ of $\mathbf{6 c}(66 \%)$. The melting point $\left(148-149^{\circ} \mathrm{C}\right)$ corresponded well with the reported one $\left(149-150^{\circ} \mathrm{C}\right)[22,22] . R_{\mathrm{f}}=0.54\left(\mathrm{CH}_{2} \mathrm{Cl}_{2}: \mathrm{CH}_{3} \mathrm{OH}=9: 1\right) ;{ }^{1} \mathrm{H}$ NMR (DMSO- $\left.d_{6}, 400 \mathrm{MHz}\right): \delta=2.27\left(\mathrm{~s}, 3 \mathrm{H}, \mathrm{CH}_{3}\right), 2.33$ (s, $\left.3 \mathrm{H}, \mathrm{ArCH}_{3}\right), 6.53\left(\mathrm{~s}, 2 \mathrm{H}, \mathrm{NH}_{2}\right), 6.98(\mathrm{~s}, 1 \mathrm{H}, \mathrm{H}-5), 7.26$ (d, $J=8.1 \mathrm{~Hz}, 2 \mathrm{H}, \mathrm{ArH}), 7.94(\mathrm{~d}, J=8.4 \mathrm{~Hz}, 2 \mathrm{H}, \mathrm{ArH}) \mathrm{ppm}$; ${ }^{13} \mathrm{C} \mathrm{NMR}$ (DMSO- $\left.d_{6}, 100 \mathrm{MHz}\right): \delta=21.10\left(\mathrm{ArCH}_{3}\right), 23.89$ $\left(\mathrm{CH}_{3}\right), 105.02(\mathrm{C}-5), 126.79,129.40(\mathrm{ArC}), 134.65,140.17$ $\left(\mathrm{ArC}_{\mathrm{q}}\right), 163.67$ (C-6), 163.86 (C-2), 168.19 (C-4) ppm; IR $(\mathrm{KBr}): \bar{v}=3361,3186,1638,1576,1550,1514,1462,1379$,
1351, 809, $799 \mathrm{~cm}^{-1}$; HRMS (EI +): $\mathrm{m} / z$ calcd. $\left(\mathrm{C}_{12} \mathrm{H}_{13} \mathrm{~N}_{3}\right)$ $\left[\mathrm{M}^{+}\right]$199.1109, found 199.1097.

4-(4-Methoxyphenyl)-6-methylpyrimidin-2-amine (6d, $\left.\mathrm{C}_{12} \mathrm{H}_{13} \mathrm{~N}_{3} \mathrm{O}\right)$ Reaction of $213 \mathrm{mg}$ of $\mathbf{5 d}(0.77 \mathrm{mmol})$ with $1.27 \mathrm{~cm}^{3}$ of concentrated aqueous $\mathrm{NH}_{3}(16.9 \mathrm{mmol})$ in 4.6 $\mathrm{cm}^{3}$ of dioxane for $3 \mathrm{~h}$ yielded $55 \mathrm{mg}$ of $\mathbf{6 d}(33 \%)$. The melting point $\left(202^{\circ} \mathrm{C}\right)$ corresponded well with the reported one $\left(204{ }^{\circ} \mathrm{C}\right)$ [24]. $R_{\mathrm{f}}=0.74\left(\mathrm{CH}_{2} \mathrm{Cl}_{2}: \mathrm{CH}_{3} \mathrm{OH}=9: 1\right) ;{ }^{1} \mathrm{H}$ NMR (DMSO- $\left.d_{6}, 400 \mathrm{MHz}\right): \delta=2.26\left(\mathrm{~s}, 3 \mathrm{H}, \mathrm{CH}_{3}\right), 3.80$ (s, $\left.3 \mathrm{H}, \mathrm{OCH}_{3}\right), 6.47\left(\mathrm{~s}, 2 \mathrm{H}, \mathrm{NH}_{2}\right), 6.96(\mathrm{~s}, 1 \mathrm{H}, \mathrm{H}-5), 7.01$ $(\mathrm{d}, J=9.2 \mathrm{~Hz}, 2 \mathrm{H}, \mathrm{ArH}), 8.01(\mathrm{~d}, J=8.8 \mathrm{~Hz}, 2 \mathrm{H}, \mathrm{ArH})$ ppm; ${ }^{13} \mathrm{C}$ NMR (DMSO- $\left.d_{6}, 100 \mathrm{MHz}\right): \delta=23.90\left(\mathrm{CH}_{3}\right)$, $55.46\left(\mathrm{OCH}_{3}\right), 104.56(\mathrm{C}-5), 114.13,128.39$ (ArC), 129.71, $161.25\left(\mathrm{ArC}_{\mathrm{q}}\right), 163.33(\mathrm{C}-4), 163.79(\mathrm{C}-2), 167.98$ (C-6) ppm; IR (KBr): $\bar{v}=3310,3176,1636,1608,1579,1545$, $1514,1463,1417,1382,1351,1249,1233,1182,1033$, $820 \mathrm{~cm}^{-1}$; HRMS $(\mathrm{EI}+): \mathrm{m} / z$ calcd. $\left(\mathrm{C}_{12} \mathrm{H}_{13} \mathrm{~N}_{3} \mathrm{O}\right)\left[\mathrm{M}^{+}\right]$ 215.1059, found 215.1045.

\section{Preparation of (pyrrolidin-1-yl)pyrimidines 7a-7d}

The compounds $\mathbf{5 a}, \mathbf{5 b}, \mathbf{5} \mathbf{c}$, or $\mathbf{5 d}$ were dissolved in dry THF and pyrrolidine was added. The reaction mixture was refluxed at $85{ }^{\circ} \mathrm{C}$ overnight or subjected to microwave irradiation. Water was added and the mixture was extracted five times with diethyl ether. The combined organic layers were washed neutral with water, dried over anhydrous $\mathrm{Na}_{2} \mathrm{SO}_{4}$, and filtered. The solvent was evaporated in vacuo giving pure compounds $\mathbf{7 a}-\mathbf{7 d}$ as white to yellowish needles. For analytical purposes they were recrystallized giving white needles.

4-Methyl-6-phenyl-2-(pyrrolidin-1-yl)pyrimidine (7a, $\left.\mathrm{C}_{15} \mathrm{H}_{17} \mathrm{~N}\right)$ Method 1: Reaction of $218 \mathrm{mg}$ of $\mathbf{5 a}(0.88 \mathrm{mmol})$ in $45 \mathrm{~cm}^{3}$ of dry THF with $157 \mathrm{mg}$ of pyrrolidine (2.21 mmol) yielded $200 \mathrm{mg}$ of $7 \mathbf{a}(95 \%)$. Method 2: Reaction of $200 \mathrm{mg}$ of $\mathbf{5 a}(0.81 \mathrm{mmol})$ in $4 \mathrm{~cm}^{3}$ of dry THF with $172 \mathrm{mg}$ of pyrrolidine $(2.42 \mathrm{mmol})$ yielded after $1 \mathrm{~h}$ microwave irradiation at $100{ }^{\circ} \mathrm{C} 148 \mathrm{mg}$ of $7 \mathbf{a}(76 \%) . R_{\mathrm{f}}=0.84$ $\left(\mathrm{CH}_{2} \mathrm{Cl}_{2}: \mathrm{CH}_{3} \mathrm{OH}=10: 1\right)$; m.p.: $88{ }^{\circ} \mathrm{C}$ (ethyl acetate); ${ }^{1} \mathrm{H}$ NMR $\left(\mathrm{CDCl}_{3}, 400 \mathrm{MHz}\right): \delta=1.90(\mathrm{t}, J=6.6 \mathrm{~Hz}, 4 \mathrm{H}$, $\left.\left(\mathrm{CH}_{2}\right)_{2}\right), 2.33$ (s, 3H, $\left.\mathrm{CH}_{3}\right), 3.60$ (br, s, $\left.4 \mathrm{H}, \mathrm{N}\left(\mathrm{CH}_{2}\right)_{2}\right), 6.72$ (s, 1H, H-5), 7.34-7.36 (m, 3H, ArH), 7.97-7.99 (m, 2H, $\mathrm{ArH}) \mathrm{ppm} ;{ }^{13} \mathrm{C} \mathrm{NMR}\left(\mathrm{CDCl}_{3}, 100 \mathrm{MHz}\right): \delta=24.45\left(\mathrm{CH}_{3}\right)$, $25.51\left(\left(\mathrm{CH}_{2}\right)_{2}\right), 46.63\left(\mathrm{~N}\left(\mathrm{CH}_{2}\right)_{2}\right), 104.33(\mathrm{C}-5), 126.93$, 128.46, 129.98 (ArC), $138.10\left(\mathrm{ArC}_{\mathrm{q}}\right), 160.70(\mathrm{C}-2), 163.95$ (C-6), 167.69 (C-4) ppm; IR (KBr): $\bar{v}=2971,2928,2857$, 1587, 1555, 1512, 1482, 1458, 1374, 1336, 1223, 1183, $771,693 \mathrm{~cm}^{-1}$; HRMS (EI+): $\mathrm{m} / z$ calcd. $\left(\mathrm{C}_{15} \mathrm{H}_{17} \mathrm{~N}_{3}\right)\left[\mathrm{M}^{+}\right]$ 239.1422 , found 239.1421 . 
4-(4-Chlorophenyl)-6-methyl-2-(pyrrolidin-1-yl)pyrimidine $\left(7 \mathrm{~b}, \mathrm{C}_{15} \mathrm{H}_{16} \mathrm{ClN}_{3}\right)$ Reaction of $300 \mathrm{mg}$ of $\mathbf{5 b}(1.06 \mathrm{mmol})$ in $5 \mathrm{~cm}^{3}$ of dry THF with $225 \mathrm{mg}$ of pyrrolidine $(3.16 \mathrm{mmol})$ yielded after $2 \mathrm{~h}$ microwave irradiation at $120{ }^{\circ} \mathrm{C} 87 \mathrm{mg}$ of 7b $(30 \%) . R_{\mathrm{f}}=0.85\left(\mathrm{CH}_{2} \mathrm{Cl}_{2}: \mathrm{CH}_{3} \mathrm{OH}=10: 1\right)$; m.p.: $87{ }^{\circ} \mathrm{C}$ $(\mathrm{MeOH}) ;{ }^{1} \mathrm{H}$ NMR $\left(\mathrm{CDCl}_{3}, 400 \mathrm{MHz}\right): \delta=1.97-2.01(\mathrm{~m}$, $\left.4 \mathrm{H},\left(\mathrm{CH}_{2}\right)_{2}\right), 2.41\left(\mathrm{~s}, 3 \mathrm{H}, \mathrm{CH}_{3}\right), 3.65-3.68\left(\mathrm{~m}, 4 \mathrm{H}, \mathrm{N}\left(\mathrm{CH}_{2}\right)_{2}\right)$, 6.76 (s, 1H, H-5), 7.41 (d, J=8.4 Hz, 2H, ArH), 8.00 (d, $J=8.8 \mathrm{~Hz}, 2 \mathrm{H}, \mathrm{ArH}) \mathrm{ppm} ;{ }^{13} \mathrm{C} \mathrm{NMR}\left(\mathrm{CDCl}_{3}, 100 \mathrm{MHz}\right)$ : $\delta=24.49\left(\mathrm{CH}_{3}\right), 25.52\left(\left(\mathrm{CH}_{2}\right)_{2}\right), 46.66\left(\mathrm{~N}\left(\mathrm{CH}_{2}\right)_{2}\right), 104.04$ (C-5), 128.25, 128.68 (ArC), 136.03, $136.56\left(\mathrm{ArC}_{\mathrm{q}}\right)$, 160.62 (C-2), 162.70 (C-4), 167.99 (C-6) ppm; IR (KBr): $\bar{v}=2866,1595,1582,1552,1513,1487,1459,1376,1338$, 1223, 1090, 1013, $806 \mathrm{~cm}^{-1}$; HRMS (EI +): $\mathrm{m} / \mathrm{z}$ calcd. $\left(\mathrm{C}_{15} \mathrm{H}_{16} \mathrm{ClN}_{3}\right)\left[\mathrm{M}^{+}\right]$273.1033, found 273.1036.

4-Methyl-6-(4-methylphenyl)-2-(pyrrolidin-1-yl)pyrimidine $\left(7 \mathrm{c}, \mathrm{C}_{16} \mathrm{H}_{19} \mathrm{~N}_{3}\right)$ Reaction of $400 \mathrm{mg}$ of $\mathbf{5 c}(1.52 \mathrm{mmol})$ in 15 $\mathrm{cm}^{3}$ of dry THF with $651 \mathrm{mg}$ of pyrrolidine $(9.15 \mathrm{mmol})$ yielded $371 \mathrm{mg}$ of $7 \mathrm{c}(96 \%) . R_{\mathrm{f}}=0.60$ (cyclohexane:ethyl acetate $=1: 3)$; m.p.: $76{ }^{\circ} \mathrm{C}$ (ethyl acetate); ${ }^{1} \mathrm{H} \mathrm{NMR}\left(\mathrm{CDCl}_{3}\right.$, $400 \mathrm{MHz}): \delta=1.96-1.99\left(\mathrm{~m}, 4 \mathrm{H},\left(\mathrm{CH}_{2}\right)_{2}\right), 2.38(\mathrm{~s}, 3 \mathrm{H}$, $\left.\mathrm{ArCH}_{3}\right), 2.39$ (s, 3H, $\left.\mathrm{CH}_{3}\right), 3.65-3.68\left(\mathrm{~m}, 4 \mathrm{H}, \mathrm{N}\left(\mathrm{CH}_{2}\right)_{2}\right)$, 6.77 (s, 1H, H-5), 7.24 (d, J=8.1 Hz, 2H, ArH), 7.96 (d, $J=8.1 \mathrm{~Hz}, 2 \mathrm{H}, \mathrm{ArH}) \mathrm{ppm} ;{ }^{13} \mathrm{C} \mathrm{NMR}\left(\mathrm{CDCl}_{3}, 100 \mathrm{MHz}\right)$ : $\delta=21.34\left(\mathrm{ArCH}_{3}\right), 24.53\left(\mathrm{CH}_{3}\right), 25.53\left(\left(\mathrm{CH}_{2}\right)_{2}\right), 46.56$ $\left(\mathrm{N}\left(\mathrm{CH}_{2}\right)_{2}\right), 104.03$ (C-5), 126.82, 129.18 (ArC), 135.36, $140.08\left(\mathrm{ArC}_{\mathrm{q}}\right), 160.88$ (C-2), 163.80 (C-6), 167.66 (C-4) ppm; IR (KBr): $\bar{v}=2944,2870,1553,1508,1482,1459$, 1375, 1337, 1220, 1182, 1111, $803 \mathrm{~cm}^{-1}$; HRMS (EI+): $\mathrm{m} / \mathrm{z}$ calcd. $\left(\mathrm{C}_{16} \mathrm{H}_{19} \mathrm{~N}_{3}\right)\left[\mathrm{M}^{+}\right] 253.1579$, found 253.1575.

4-(4-Methoxyphenyl)-6-methyl-2-(pyrrolidin-1-yl)pyrimidine $\left(7 \mathrm{~d}, \mathrm{C}_{16} \mathrm{H}_{19} \mathrm{~N}_{3} \mathrm{O}\right)$ Reaction of $300 \mathrm{mg}$ of $\mathbf{5 d}(1.08 \mathrm{mmol})$ in $10 \mathrm{~cm}^{3}$ of dry THF with $460 \mathrm{mg}$ of pyrrolidine $(6.47 \mathrm{mmol})$ yielded an oil which was purified by means of $\mathrm{CC}$ with cyclohexane:ethyl acetate (1:1) as eluent giving $276 \mathrm{mg}$ of 7d $(95 \%) . R_{\mathrm{f}}=0.48$ (cyclohexane:ethyl acetate $=1: 1$ ); m.p.: $88^{\circ} \mathrm{C}$ (ethyl acetate); ${ }^{1} \mathrm{H}$ NMR $\left(\mathrm{CDCl}_{3}, 400 \mathrm{MHz}\right)$ : $\delta=1.96-1.99\left(\mathrm{~m}, 4 \mathrm{H},\left(\mathrm{CH}_{2}\right)_{2}\right), 2.39\left(\mathrm{~s}, 3 \mathrm{H}, \mathrm{CH}_{3}\right), 3.65-$ $3.68\left(\mathrm{~m}, 4 \mathrm{H}, \mathrm{N}\left(\mathrm{CH}_{2}\right)_{2}\right), 3.84\left(\mathrm{~s}, 3 \mathrm{H}, \mathrm{OCH}_{3}\right), 6.74(\mathrm{~s}, 1 \mathrm{H}$, H-5), 6.95 (d, $J=8.4 \mathrm{~Hz}, 2 \mathrm{H}, \mathrm{ArH}), 8.03(\mathrm{~d}, J=8.8 \mathrm{~Hz}, 2 \mathrm{H}$, $\mathrm{ArH}) \mathrm{ppm} ;{ }^{13} \mathrm{C} \mathrm{NMR}\left(\mathrm{CDCl}_{3}, 100 \mathrm{MHz}\right): \delta=24.53\left(\mathrm{CH}_{3}\right)$, $25.52\left(\left(\mathrm{CH}_{2}\right)_{2}\right), 46.54\left(\mathrm{~N}\left(\mathrm{CH}_{2}\right)_{2}\right), 55.26\left(\mathrm{OCH}_{3}\right), 103.54$ (C-5), 113.76, $128.32(\mathrm{ArC}), 130.62\left(\mathrm{ArC}_{\mathrm{q}}\right), 160.83(\mathrm{C}-2)$, $161.21\left(\mathrm{ArC}_{\mathrm{q}}\right), 163.32(\mathrm{C}-4), 167.52(\mathrm{C}-6) \mathrm{ppm}$; IR (KBr): $\bar{v}=2955,2875,1607,1587,1553,1512,1483,1458,1379$, $1351,1338,1249,1173,1109,1033,839,808,789 \mathrm{~cm}^{-1}$; HRMS (EI+): $m / z$ calcd. $\left(\mathrm{C}_{16} \mathrm{H}_{19} \mathrm{~N}_{3} \mathrm{O}\right)\left[\mathrm{M}^{+}\right] 269.1528$, found 269.1528 .

\section{Preparation of 2-(4-methylpiperazin-1-yl) pyrimidines $8 \mathrm{a}-\mathbf{8 d}$}

The compounds $5 \mathbf{a}, \mathbf{5 b}, \mathbf{5 c}$, or $\mathbf{5 d}$ were dissolved in dry THF and 1-methylpiperazine was added. The reaction mixture was refluxed at $100^{\circ} \mathrm{C}$ overnight or subjected to microwave irradiation. Water was added and the mixture was extracted five times with diethyl ether. The combined organic layers were washed neutral with water, dried over anhydrous $\mathrm{Na}_{2} \mathrm{SO}_{4}$ and filtered. The solvent was evaporated in vacuo giving a resin which was further purified.

4-Methyl-2-(4-methylpiperazin-1-yl)-6-phenylpyrimidine $\left(8 \mathrm{a}, \mathrm{C}_{16} \mathrm{H}_{20} \mathrm{~N}_{4}\right)$ Reaction of $300 \mathrm{mg}$ of $\mathbf{5 a}(1.21 \mathrm{mmol})$ in $12 \mathrm{~cm}^{3}$ of dry THF with $726 \mathrm{mg}$ of 1-methylpiperazine ( $7.24 \mathrm{mmol}$ ) yielded a yellow resin which was purified by means of $\mathrm{CC}\left(\mathrm{CH}_{2} \mathrm{Cl}_{2}: \mathrm{CH}_{3} \mathrm{OH}=40: 1\right.$, Alox neutral) giving $245 \mathrm{mg}$ of $\mathbf{8 a}(75 \%)$ as a yellow oil which crystallized upon cooling. $R_{\mathrm{f}}=0.62\left(\mathrm{CH}_{2} \mathrm{Cl}_{2}: \mathrm{CH}_{3} \mathrm{OH}=40: 1\right.$, Alox neutral); m.p.: $65^{\circ} \mathrm{C} ;{ }^{1} \mathrm{H}$ NMR $\left(\mathrm{CDCl}_{3}, 400 \mathrm{MHz}\right): \delta=2.36$ (s, $\left.3 \mathrm{H}, \mathrm{NCH}_{3}\right), 2.40\left(\mathrm{~s}, 3 \mathrm{H}, \mathrm{CH}_{3}\right), 2.50-2.53(\mathrm{~m}, 4 \mathrm{H}, \mathrm{H}-3$ '), 3.96-3.98 (m, 4H, H-2'), 6.84 (s, 1H, H-5), 7.44-7.45 (m, $3 \mathrm{H}, \mathrm{ArH}), 8.02-8.04(\mathrm{~m}, 2 \mathrm{H}, \mathrm{ArH}) \mathrm{ppm} ;{ }^{13} \mathrm{C} \mathrm{NMR}\left(\mathrm{CDCl}_{3}\right.$, $100 \mathrm{MHz}): \delta=24.50\left(\mathrm{CH}_{3}\right), 43.62\left(\mathrm{C}-2^{\prime}\right), 46.21\left(\mathrm{NCH}_{3}\right)$, 55.04 (C-3'), 105.32 (C-5), 126.93, 128.51, 130.11 (ArC), $137.93\left(\mathrm{ArC}_{\mathrm{q}}\right), 162.00(\mathrm{C}-2), 164.00$ (C-6), 168.06 (C-4) ppm; IR (KBr): $\bar{v}=2924,2794,1558,1493,1443,1368$, 1345, 1300, 1272, 1223, 1188, 1173, 1073, 1007, 994, 890, 815, 764, $687 \mathrm{~cm}^{-1}$; HRMS (EI +): $\mathrm{m} / z$ calcd. $\left(\mathrm{C}_{16} \mathrm{H}_{20} \mathrm{~N}_{4}\right)$ $\left[\mathrm{M}^{+}\right]$268.1688, found 268.1693.

4-(4-Chlorophenyl)-6-methyl-2-(4-methylpiperazin-1-yl)pyrimidine (8b, $\mathrm{C}_{16} \mathrm{H}_{19} \mathrm{CIN}_{4}$ ) Reaction of $375 \mathrm{mg}$ of $\mathbf{5 b}$ $(1.33 \mathrm{mmol})$ in $5 \mathrm{~cm}^{3}$ of dry THF with $787 \mathrm{mg}$ of 1-methylpiperazine $(7.86 \mathrm{mmol})$ yielded after $5 \mathrm{~h}$ microwave irradiation at $120^{\circ} \mathrm{C}$ a yellow resin. It was purified by means of CC $\left(\mathrm{CH}_{2} \mathrm{Cl}_{2}: \mathrm{CH}_{3} \mathrm{OH}=10: 1\right)$ giving $235 \mathrm{mg}$ of $\mathbf{8 b}(58 \%)$ as a white amorphous solid. $R_{\mathrm{f}}=0.43\left(\mathrm{CH}_{2} \mathrm{Cl}_{2}: \mathrm{CH}_{3} \mathrm{OH}=10: 1\right)$; ${ }^{1} \mathrm{H}$ NMR (DMSO- $\left.d_{6}, 400 \mathrm{MHz}\right): \delta=2.20\left(\mathrm{~s}, 3 \mathrm{H}, \mathrm{NCH}_{3}\right.$ ), 2.33 (s, 3H, $\mathrm{CH}_{3}$ ), 2.34-2.36 (m, 4H, H-3'), 3.75-3.82 (m, 4H, H-2'), 7.11 (s, 1H, H-5), 7.53 (d, $J=8.4 \mathrm{~Hz}, 2 \mathrm{H}, \mathrm{ArH})$, $8.11(\mathrm{~d}, J=8.4 \mathrm{~Hz}, 2 \mathrm{H}, \mathrm{ArH}) \mathrm{ppm} ;{ }^{13} \mathrm{C}$ NMR (DMSO- $d_{6}$, $100 \mathrm{MHz}): \delta=24.36\left(\mathrm{CH}_{3}\right), 43.46\left(\mathrm{C}-2^{\prime}\right), 46.06\left(\mathrm{NCH}_{3}\right)$, 54.67 (C-3'), 105.06 (C-5), 128.71, 128.93 (ArC), 135.41, $136.11\left(\mathrm{ArC}_{\mathrm{q}}\right), 161.59(\mathrm{C}-2), 161.91(\mathrm{C}-4), 168.61(\mathrm{C}-6)$ ppm; IR (KBr): $\bar{v}=2930,2795,1585,1556,1508,1491$, 1447, 1371, 1345, 1303, 1283, 1269, 1093, 1006, 995, $804 \mathrm{~cm}^{-1}$; HRMS $(\mathrm{EI}+): \mathrm{m} / z$ calcd. $\left(\mathrm{C}_{16} \mathrm{H}_{19} \mathrm{ClN}_{4}\right)\left[\mathrm{M}^{+}\right]$ 302.1298 , found 302.1310 .

4-Methyl-6-(4-methylphenyl)-2-(4-methylpiperazin-1-yl)pyrimidine $\left(8 \mathrm{c}, \mathrm{C}_{17} \mathrm{H}_{22} \mathrm{~N}_{4}\right.$ ) Reaction of $400 \mathrm{mg}$ of $5 \mathrm{c}$ 
$(1.52 \mathrm{mmol})$ in $3 \mathrm{~cm}^{3}$ of dry THF with $916 \mathrm{mg}$ of 1 -methylpiperazine $(9.14 \mathrm{mmol})$ yielded after $7 \mathrm{~h}$ microwave irradiation at $120^{\circ} \mathrm{C}$ a resin. It was purified by means of CC $\left(\mathrm{CH}_{2} \mathrm{Cl}_{2}: \mathrm{CH}_{3} \mathrm{OH}=10: 1\right)$ giving $334 \mathrm{mg}$ of $8 \mathrm{c}(78 \%)$ as an orange oil which crystallized upon cooling. $R_{\mathrm{f}}=0.43$ $\left(\mathrm{CH}_{2} \mathrm{Cl}_{2}: \mathrm{CH}_{3} \mathrm{OH}=10: 1\right)$; m.p.: $73{ }^{\circ} \mathrm{C} ;{ }^{1} \mathrm{H}$ NMR $\left(\mathrm{CDCl}_{3}\right.$, $400 \mathrm{MHz}): \delta=2.34$ (s, 3H, $\left.\mathrm{NCH}_{3}\right), 2.38\left(\mathrm{~s}, 3 \mathrm{H}, \mathrm{CH}_{3}\right), 2.39$ (s, 3H, $\mathrm{ArCH}_{3}$ ), 2.48-2.50 (m, 4H, H-3'), 3.94-3.96 (m, 4H, H-2'), 6.80 (s, 1H, H-5), 7.24 (d, J=8.1 Hz, 2H, ArH), 7.93 (d, $J=8.1 \mathrm{~Hz}, 2 \mathrm{H}, \mathrm{ArH}) \mathrm{ppm} ;{ }^{13} \mathrm{C} \mathrm{NMR}\left(\mathrm{CDCl}_{3}, 100 \mathrm{MHz}\right)$ : $\delta=21.33\left(\mathrm{ArCH}_{3}\right), 24.46\left(\mathrm{CH}_{3}\right), 43.67\left(\mathrm{C}-2^{\prime}\right), 46.25$ $\left(\mathrm{NCH}_{3}\right), 55.06\left(\mathrm{C}-3^{\prime}\right), 104.94(\mathrm{C}-5), 126.81,129.20(\mathrm{ArC})$, 135.10, $140.25\left(\mathrm{ArC}_{\mathrm{q}}\right), 161.99(\mathrm{C}-2), 163.91(\mathrm{C}-6), 167.82$ (C-4) ppm; IR (KBr): $\bar{v}=2930,2793,1585,1570,1556$, 1504, 1447, 1371, 1345, 1300, 1285, 1272, 1008, $804 \mathrm{~cm}^{-1}$; HRMS (EI+): $m / z$ calcd. $\left(\mathrm{C}_{17} \mathrm{H}_{22} \mathrm{~N}_{4}\right)\left[\mathrm{M}^{+}\right] 282.1844$, found 282.1850 .

4-(4-Methoxyphenyl)-6-methyl-2-(4-methylpiperazin-1-yl)pyrimidine (8d, $\mathrm{C}_{17} \mathrm{H}_{22} \mathrm{~N}_{4}$ ) Reaction of $250 \mathrm{mg}$ of $\mathbf{5 d}$ $(0.90 \mathrm{mmol})$ in $9 \mathrm{~cm}^{3}$ of dry THF with $540 \mathrm{mg}$ of 1 -methylpiperazine $(5.39 \mathrm{mmol})$ yielded after 3 days refluxing at $100{ }^{\circ} \mathrm{C}$ a residue which was crystallized from ethyl acetate giving $141 \mathrm{mg}$ of $\mathbf{8 d}(53 \%)$ as white needles. $R_{\mathrm{f}}=0.43$ $\left(\mathrm{CH}_{2} \mathrm{Cl}_{2}: \mathrm{CH}_{3} \mathrm{OH}=10: 1\right)$; m.p.: $93{ }^{\circ} \mathrm{C} ;{ }^{1} \mathrm{H}$ NMR $\left(\mathrm{CDCl}_{3}\right.$, $400 \mathrm{MHz}): \delta=2.34\left(\mathrm{~s}, 3 \mathrm{H}, \mathrm{NCH}_{3}\right), 2.38\left(\mathrm{~s}, 3 \mathrm{H}, \mathrm{CH}_{3}\right.$ ), 2.48-2.50 (m, 4H, H-3'), 3.84 (s, 3H, $\mathrm{OCH}_{3}$ ), 3.95 (br, s, 4H, H-2'), 6.77 (s, 1H, H-5), 6.95 (d, J=8.4 Hz, 2H, ArH), 8.01 (d, $J=8.4 \mathrm{~Hz}, 2 \mathrm{H}, \mathrm{ArH}) \mathrm{ppm} ;{ }^{13} \mathrm{C} \mathrm{NMR}\left(\mathrm{CDCl}_{3}, 100 \mathrm{MHz}\right)$ : $\delta=24.45\left(\mathrm{CH}_{3}\right), 43.67\left(\mathrm{C}-2^{\prime}\right), 46.25\left(\mathrm{NCH}_{3}\right), 55.06\left(\mathrm{C}-3^{\prime}\right)$, $55.24\left(\mathrm{OCH}_{3}\right), 104.46(\mathrm{C}-5), 113.78,128.33(\mathrm{ArC}), 130.34$, $161.30\left(\mathrm{ArC}_{\mathrm{q}}\right), 161.95$ (C-2), 163.44 (C-4), 167.67 (C-6) ppm; IR (KBr): $\bar{v} 2936,2788,1610,1586,1570,1557,1514$, 1492, 1459, 1350, 1301, 1286, 1270, 1258, 1172, 1027, $1009,813 \mathrm{~cm}^{-1}$; HRMS (EI +): $\mathrm{m} / z$ calcd. $\left(\mathrm{C}_{17} \mathrm{H}_{22} \mathrm{~N}_{4} \mathrm{O}\right)$ $\left[\mathrm{M}^{+}\right]$298.1794, found 298.1793 .

\section{Preparation of $\mathrm{N}$-[5-(diethylamino) pentan-2-yl]pyrimidin-2-amines 9a-9d}

The compounds $\mathbf{5 a}, \mathbf{5 b}, \mathbf{5} \mathbf{c}$, or $\mathbf{5 d}$ were dissolved in dry THF and 2-amino-5-(diethylamino)pentane was added. The reaction mixture was subjected to microwave irradiation. Water was added and the mixture was extracted five times with diethyl ether. The combined organic layers were washed neutral with water, dried over anhydrous $\mathrm{Na}_{2} \mathrm{SO}_{4}$ and filtered. The solvent was evaporated in vacuo giving residues which were further purified.

$\mathrm{N}$-[5-(Diethylamino)pentan-2-yl]-4-methyl-6-phenylpyrimidin-2-amine $\left(9 \mathrm{a}, \mathrm{C}_{20} \mathrm{H}_{30} \mathrm{~N}_{4}\right)$ Reaction of $200 \mathrm{mg}$ of $5 \mathbf{a}(0.81 \mathrm{mmol})$ in $4 \mathrm{~cm}^{3}$ of dry THF with $766 \mathrm{mg}$ of 2-amino-5-(diethylamino)pentane $(4.84 \mathrm{mmol})$ yielded after $12 \mathrm{~h}$ microwave irradiation at $120{ }^{\circ} \mathrm{C}$ a residue which was purified by means of $\mathrm{CC}\left(\mathrm{CH}_{2} \mathrm{Cl}_{2}: \mathrm{CH}_{3} \mathrm{OH}=40: 1\right.$, Alox neutral) giving $122 \mathrm{mg}$ of $\mathbf{9 a}(46 \%)$ as yellow oil. $R_{\mathrm{f}}=0.24$ $\left(\mathrm{CH}_{2} \mathrm{Cl}_{2}: \mathrm{CH}_{3} \mathrm{OH}=40: 1\right.$, Alox neutral $) ;{ }^{1} \mathrm{H} \mathrm{NMR}\left(\mathrm{CDCl}_{3}\right.$, $400 \mathrm{MHz}): \delta=1.03\left(\mathrm{t}, J=7.1 \mathrm{~Hz}, 6 \mathrm{H}, \mathrm{H}-2^{\prime \prime}\right), 1.26(\mathrm{~d}$, $\left.J=6.5 \mathrm{~Hz}, 3 \mathrm{H}, \mathrm{H}-1^{\prime}\right), 1.54-1.65$ (m, 4H, H-3', H-4'), 2.38 (s, 3H, $\left.\mathrm{CH}_{3}\right), 2.50-2.55\left(\mathrm{~m}, 2 \mathrm{H}, \mathrm{H}-5^{\prime}\right), 2.56(\mathrm{q}, J=7.1 \mathrm{~Hz}$, $\left.4 \mathrm{H}, \mathrm{H}-1^{\prime \prime}\right), 4.23-4.28$ (m, 1H, H-2'), 4.96 (d, J=8.3 Hz, 1H, $\mathrm{NH}), 6.84$ (s, 1H, H-5), 7.44-7.46 (m, 3H, ArH), 8.01-8.02 (m, $2 \mathrm{H}, \mathrm{ArH}) \mathrm{ppm} ;{ }^{13} \mathrm{C} \mathrm{NMR}\left(\mathrm{CDCl}_{3}, 100 \mathrm{MHz}\right): \delta=11.28$ $\left(\mathrm{C}-2^{\prime \prime}\right), 21.12\left(\mathrm{C}-1^{\prime}\right), 23.13\left(\mathrm{C}-4^{\prime}\right), 24.32\left(\mathrm{CH}_{3}\right), 35.11$ (C-3'), 46.48 (C-2'), $46.71\left(\mathrm{C}-1^{\prime \prime}\right), 52.71\left(\mathrm{C}-5^{\prime}\right), 105.75$ (C-5), 126.92, 128.55, $130.13(\mathrm{ArC}), 137.85\left(\mathrm{ArC}_{\mathrm{q}}\right), 162.27$ (C-2), 164.44 (C-6), 168.25 (C-4) ppm; IR (KBr): $\bar{v}=3268$, 2965, 1574, 1551, 1495, 1458, 1373, 1346, 1203, 1069, 767, $693 \mathrm{~cm}^{-1}$; HRMS (EI+): $\mathrm{m} / z$ calcd. $\left(\mathrm{C}_{20} \mathrm{H}_{30} \mathrm{~N}_{4}\right)\left[\mathrm{M}^{+}\right]$ 326.2470, found 326.2471.

4-(4-Chlorophenyl)- $\mathrm{N}$-[5-(diethylamino)pentan-2-yl]-6-methylpyrimidin-2-amine $\left(9 \mathrm{~b}, \mathrm{C}_{20} \mathrm{H}_{29} \mathrm{ClN}_{4}\right)$ Reaction of $246 \mathrm{mg}$ of $5 \mathbf{b}(0.87 \mathrm{mmol})$ in $5 \mathrm{~cm}^{3}$ of dry THF with $826 \mathrm{mg}$ of 2-amino-5-(diethylamino)pentane $(5.22 \mathrm{mmol})$ yielded after $7.5 \mathrm{~h}$ microwave irradiation at $120^{\circ} \mathrm{C}$ a residue which was purified by means of $\mathrm{CC}\left(\mathrm{CH}_{2} \mathrm{Cl}_{2}: \mathrm{CH}_{3} \mathrm{OH}=40: 1\right.$, Alox neutral) giving $196 \mathrm{mg}$ of $\mathbf{9 b}(62 \%)$ as yellow oil. $R_{\mathrm{f}}=0.70$ $\left(\mathrm{CH}_{2} \mathrm{Cl}_{2}: \mathrm{CH}_{3} \mathrm{OH}=10: 1\right) ;{ }^{1} \mathrm{H} \mathrm{NMR}\left(\mathrm{CDCl}_{3}, 400 \mathrm{MHz}\right)$ : $\delta=1.01\left(\mathrm{t}, J=7.2 \mathrm{~Hz}, 6 \mathrm{H}, \mathrm{H}-2^{\prime \prime}\right), 1.25(\mathrm{~d}, J=6.5 \mathrm{~Hz}, 3 \mathrm{H}$, H-1'), 1.53-1.62 (m, 4H, H-3', H-4'), 2.37 (s, 3H, $\mathrm{CH}_{3}$ ), 2.45-2.48 (m, 2H, H-5'), 2.52 (q, $\left.J=7.2 \mathrm{~Hz}, 4 \mathrm{H}, \mathrm{H}-1^{\prime \prime}\right)$, $4.20-4.25\left(\mathrm{~m}, 1 \mathrm{H}, \mathrm{H}-2^{\prime}\right), 5.02(\mathrm{~d}, J=8.3 \mathrm{~Hz}, 1 \mathrm{H}, \mathrm{NH})$, 6.79 (s, 1H, H-5), 7.41 (d, J=8.5 Hz, 2H, ArH), 7.96 (d, $J=8.4 \mathrm{~Hz}, 2 \mathrm{H}, \mathrm{ArH}) \mathrm{ppm} ;{ }^{13} \mathrm{C} \mathrm{NMR}\left(\mathrm{CDCl}_{3}, 100 \mathrm{MHz}\right)$ : $\delta=11.44\left(\mathrm{C}-2^{\prime \prime}\right), 21.03\left(\mathrm{C}-1^{\prime}\right), 23.38\left(\mathrm{C}-4^{\prime}\right), 24.29\left(\mathrm{CH}_{3}\right)$, 35.08 (C-3'), 46.53 (C-2'), 46.70 (C-1'), 52.78 (C-5'), $105.36(\mathrm{C}-5), 128.19,128.71(\mathrm{ArC}), 136.12,136.27\left(\mathrm{ArC}_{\mathrm{q}}\right)$, 162.21 (C-2), 163.11 (C-4), 168.45 (C-6) ppm; IR (KBr): $\bar{v}=3268,2965,2798,1573,1549,1491,1456,1402,1374$, 1342, 1091, 1013, $808 \mathrm{~cm}^{-1}$; HRMS (EI +$): \mathrm{m} / z$ calcd. $\left(\mathrm{C}_{20} \mathrm{H}_{29} \mathrm{ClN}_{4}\right)\left[\mathrm{M}^{+}\right]$360.2081, found 360.2103.

$N$-[5-(Diethylamino)pentan-2-yl]-4-methyl-6-(4-methylphenyl)pyrimidin-2-amine $\left(9 \mathrm{c}, \mathrm{C}_{21} \mathrm{H}_{32} \mathrm{~N}_{4}\right)$ Reaction of $300 \mathrm{mg}$ of $\mathbf{5 c}(1.14 \mathrm{mmol})$ in $3 \mathrm{~cm}^{3}$ of dry THF with $1.09 \mathrm{~g}$ of 2-amino-5-(diethylamino)pentane $(6.86 \mathrm{mmol})$ yielded after $13 \mathrm{~h}$ microwave irradiation at $120{ }^{\circ} \mathrm{C}$ a residue which was purified by means of $\mathrm{CC}\left(\mathrm{CH}_{2} \mathrm{Cl}_{2}: \mathrm{CH}_{3} \mathrm{OH}=40: 1\right.$, Alox neutral) giving $313 \mathrm{mg}$ of $9 \mathrm{c}(81 \%)$ as orange oil. $R_{\mathrm{f}}=0.23$ $\left(\mathrm{CH}_{2} \mathrm{Cl}_{2}: \mathrm{CH}_{3} \mathrm{OH}=40: 1\right.$, Alox neutral); ${ }^{1} \mathrm{H} \mathrm{NMR}\left(\mathrm{CDCl}_{3}\right.$, $400 \mathrm{MHz}): \delta=1.00\left(\mathrm{t}, J=7.1 \mathrm{~Hz}, 6 \mathrm{H}, \mathrm{H}-2^{\prime \prime}\right), 1.24(\mathrm{~d}$, $\left.J=6.6 \mathrm{~Hz}, 3 \mathrm{H}, \mathrm{H}-1^{\prime}\right), 1.51-1.60$ (m, 4H, H-3', H-4'), 2.36 (s, $\left.3 \mathrm{H}, \mathrm{CH}_{3}\right), 2.40$ (s, $\left.3 \mathrm{H}, \mathrm{ArCH}_{3}\right), 2.43-2.46\left(\mathrm{~m}, 2 \mathrm{H}, \mathrm{H}-5^{\prime}\right)$, 2.51 (q, $\left.J=7.1 \mathrm{~Hz}, 4 \mathrm{H}, \mathrm{H}-1^{\prime \prime}\right), 4.21-4.24\left(\mathrm{~m}, 1 \mathrm{H}, \mathrm{H}-2^{\prime}\right)$, 
$4.97(\mathrm{~d}, J=8.1 \mathrm{~Hz}, 1 \mathrm{H}, \mathrm{NH}), 6.80(\mathrm{~s}, 1 \mathrm{H}, \mathrm{H}-5), 7.24(\mathrm{~d}$, $J=8.1 \mathrm{~Hz}, 2 \mathrm{H}, \mathrm{ArH}), 7.92(\mathrm{~d}, J=8.1 \mathrm{~Hz}, 2 \mathrm{H}, \mathrm{ArH}) \mathrm{ppm}$; ${ }^{13} \mathrm{C} \mathrm{NMR}\left(\mathrm{CDCl}_{3}, 100 \mathrm{MHz}\right): \delta=11.56\left(\mathrm{C}-2^{\prime \prime}\right), 21.02$ $\left(\mathrm{C}-1^{\prime}\right), 21.33\left(\mathrm{ArCH}_{3}\right), 23.45\left(\mathrm{C}-4^{\prime}\right), 24.24\left(\mathrm{CH}_{3}\right), 35.14$ $\left(\mathrm{C}-3^{\prime}\right), 46.50\left(\mathrm{C}-2^{\prime}\right), 46.71\left(\mathrm{C}-1^{\prime \prime}\right), 52.84\left(\mathrm{C}-5^{\prime}\right), 105.30$ (C-5), 126.79, 129.21 (ArC), 135.01, $140.25\left(\mathrm{ArC}_{\mathrm{q}}\right), 162.21$ (C-2), 164.32 (C-6), 167.96 (C-4) ppm; IR (KBr): $\bar{v}=2965$, $1574,1549,1510,1454,1374,1345,1182,806 \mathrm{~cm}^{-1}$; HRMS (EI+): $m / z$ calcd. $\left(\mathrm{C}_{21} \mathrm{H}_{32} \mathrm{~N}_{4}\right)\left[\mathrm{M}^{+}\right] 340.2627$, found 340.2636 .

$\mathrm{N}$-[5-(Diethylamino)pentan-2-yl]-4-(4-methoxyphenyl)6-methylpyrimidin-2-amine (9d, $\left.\mathrm{C}_{21} \mathrm{H}_{32} \mathrm{~N}_{4} \mathrm{O}\right)$ Reaction of $300 \mathrm{mg}$ of $\mathbf{5 d}(1.08 \mathrm{mmol})$ in $3 \mathrm{~cm}^{3}$ of dry THF with $1.02 \mathrm{~g}$ of 2-amino-5-(diethylamino)pentane $(6.47 \mathrm{mmol})$ yielded after $6 \mathrm{~h}$ microwave irradiation at $120^{\circ} \mathrm{C}$ a residue which was purified by means of $\mathrm{CC}\left(\mathrm{CH}_{2} \mathrm{Cl}_{2}: \mathrm{CH}_{3} \mathrm{OH}=40: 1\right.$, Alox neutral). The fractions containing the product were combined, solvents evaporated, and the residue was subjected again to $\mathrm{CC}\left(\mathrm{CH}_{2} \mathrm{Cl}_{2}: \mathrm{CH}_{3} \mathrm{OH}=60: 1\right.$, Alox neutral) giving $250 \mathrm{mg}$ of $9 \mathrm{~d}(65 \%)$ as yellow oil. $R_{\mathrm{f}}=0.35$ $\left(\mathrm{CH}_{2} \mathrm{Cl}_{2}: \mathrm{CH}_{3} \mathrm{OH}=60: 1\right.$, Alox neutral $) ;{ }^{1} \mathrm{H} \mathrm{NMR}\left(\mathrm{CDCl}_{3}\right.$, $400 \mathrm{MHz}): \delta=1.00\left(\mathrm{t}, J=7.3 \mathrm{~Hz}, 6 \mathrm{H}, \mathrm{H}-2^{\prime \prime}\right), 1.24(\mathrm{~d}$, $\left.J=6.6 \mathrm{~Hz}, 3 \mathrm{H}, \mathrm{H}-1^{\prime}\right), 1.50-1.60$ (m, 4H, H-3', H-4'), 2.35 (s, 3H, $\left.\mathrm{CH}_{3}\right), 2.43-2.46\left(\mathrm{~m}, 2 \mathrm{H}, \mathrm{H}-5^{\prime}\right), 2.51$ (q, $J=7.3 \mathrm{~Hz}$, $\left.4 \mathrm{H}, \mathrm{H}-1^{\prime \prime}\right), 3.85$ (s, 3H, $\left.\mathrm{OCH}_{3}\right), 4.21-4.24\left(\mathrm{~m}, 1 \mathrm{H}, \mathrm{H}-2^{\prime}\right)$, $4.96(\mathrm{~d}, J=8.1 \mathrm{~Hz}, 1 \mathrm{H}, \mathrm{NH}), 6.77$ (s, 1H, H-5), 6.96 (d, $J=8.8 \mathrm{~Hz}, 2 \mathrm{H}, \mathrm{ArH}), 8.00(\mathrm{~d}, J=8.8 \mathrm{~Hz}, 2 \mathrm{H}, \mathrm{ArH}) \mathrm{ppm} ;{ }^{13} \mathrm{C}$ NMR ( $\left.\mathrm{CDCl}_{3}, 100 \mathrm{MHz}\right): \delta=11.56\left(\mathrm{C}-2^{\prime \prime}\right), 21.02\left(\mathrm{C}-1^{\prime}\right)$, 23.46 (C-4'), $24.24\left(\mathrm{CH}_{3}\right), 35.15\left(\mathrm{C}-3^{\prime}\right), 46.49\left(\mathrm{C}-2^{\prime}\right), 46.71$ $\left(\mathrm{C}-1^{\prime \prime}\right), 52.85\left(\mathrm{C}-5^{\prime}\right), 55.26\left(\mathrm{OCH}_{3}\right), 104.80(\mathrm{C}-5), 113.80$, 128.33 (ArC), 130.25, $161.30\left(\mathrm{ArC}_{\mathrm{q}}\right), 162.16(\mathrm{C}-2), 163.85$ (C-4), 167.81 (C-6) ppm; IR (KBr): $\bar{v}=2964,1575,1547$, 1510, 1453, 1374, 1348, 1305, 1294, 1250, 1171, 1033, $810 \mathrm{~cm}^{-1}$; HRMS (EI +$): \mathrm{m} / z$ calcd. $\left(\mathrm{C}_{21} \mathrm{H}_{32} \mathrm{~N}_{4} \mathrm{O}\right)\left[\mathrm{M}^{+}\right]$ 356.2576 , found 356.2585 .

\section{Preparation of $\mathrm{N}$-[2-[(pyrimidin-2-yl)amino]- ethyl]-7-chloroquinolin-4-amines 10a-10d}

The compounds $\mathbf{5 a}, \mathbf{5 b}, \mathbf{5 c}$, or $\mathbf{5 d}$ were dissolved in dry THF and $N$-(2-aminoethyl)-7-chloroquinolin-4-amine was added. The reaction mixture was subjected to microwave irradiation. The solution was transferred into a separatory funnel and water was added. The mixture was extracted fives times. The combined organic layers were washed with water, dried over anhydrous $\mathrm{Na}_{2} \mathrm{SO}_{4}$, and filtered. The solvent was evaporated in vacuo giving a residue which was further purified.

7-Chloro- $N$-[2-[(4-methyl-6-phenylpyrimidin-2-yl)amino]ethyl]quinolin-4-amine $\left(10 \mathrm{a}, \mathrm{C}_{22} \mathrm{H}_{20} \mathrm{CIN}_{5}\right)$ Reaction of $400 \mathrm{mg}$ of $5 \mathbf{a}(1.61 \mathrm{mmol})$ in $8 \mathrm{~cm}^{3}$ of dry THF with $1.43 \mathrm{~g}$ of $\mathrm{N}$-(2-aminoethyl)-7-chloroquinolin-4-amine (6.44 mmol) yielded after $7 \mathrm{~h}$ microwave irradiation at $120^{\circ} \mathrm{C}$ and extraction with $\mathrm{CH}_{2} \mathrm{Cl}_{2}$ a residue. This was purified using $\mathrm{CC}$ $\left(\mathrm{CH}_{2} \mathrm{Cl}_{2}: \mathrm{CH}_{3} \mathrm{OH}=40: 1\right.$, Alox neutral $)$ giving $285 \mathrm{mg}$ of 10a $(45 \%)$ as white foam. $R_{\mathrm{f}}=0.36\left(\mathrm{CH}_{2} \mathrm{Cl}_{2}: \mathrm{CH}_{3} \mathrm{OH}=40: 1\right.$, Alox neutral); ${ }^{1} \mathrm{H}$ NMR (DMSO- $\left.d_{6}, 400 \mathrm{MHz}\right): \delta=2.33$ (br, $\left.\mathrm{s}, 3 \mathrm{H}, \mathrm{CH}_{3}\right), 3.46-3.51\left(\mathrm{~m}, 2 \mathrm{H}, \mathrm{H}-3^{\prime}\right), 3.58-3.72(\mathrm{~m}, 2 \mathrm{H}$, H-2'), 6.62-6.88 (m, 1H, ArH), 7.07 (s, 1H, H-5), 7.29-7.50 (m, 6H, 2NH, ArH), 7.77 (s, 1H, ArH), 8.04-8.24 (m, 3H, ArH), 8.28-8.42 (m, 1H, ArH) ppm; ${ }^{13} \mathrm{C}$ NMR (DMSO$\left.d_{6}, 100 \mathrm{MHz}\right): \delta=24.04\left(\mathrm{CH}_{3}\right), 39.07\left(\mathrm{C}-2^{\prime}\right), 42.45\left(\mathrm{C}-3^{\prime}\right)$, 98.96 ( $\mathrm{ArC}), 105.61(\mathrm{C}-5), 117.60\left(\mathrm{ArC}_{\mathrm{q}}\right), 124.10,124.20$, 126.96, 127.73, 128.90, 130.60 (ArC), 133.54, 137.54, 149.29, $150.33\left(\mathrm{ArC}_{\mathrm{q}}\right), 152.07(\mathrm{ArC}), 162.75(\mathrm{C}-2), 163.53$ (C-6), 168.55 (C-4) ppm; IR (KBr): $\bar{v}=3269,2953,1582$, 1556, 1429, 1374, 1348, 1299, 1231, 1140, $769 \mathrm{~cm}^{-1}$; HRMS (EI +): $\mathrm{m} / z$ calcd. $\left(\mathrm{C}_{22} \mathrm{H}_{20} \mathrm{ClN}_{5}\right)\left[\mathrm{M}^{+}\right]$389.1407, found 389.1404 .

7-Chloro-N-[2-[[4-(4-chlorophenyl)-6-methylpyrimidin-2-yl]amino]ethyl]quinolin-4-amine (10b, $\left.\mathrm{C}_{22} \mathrm{H}_{19} \mathrm{Cl}_{2} \mathrm{~N}_{5}\right)$ Reaction of $226 \mathrm{mg}$ of $\mathbf{5 b}(0.8 \mathrm{mmol})$ in $5 \mathrm{~cm}^{3}$ of dry THF with $714 \mathrm{mg}$ of $N$-(2-aminoethyl)-7-chloroquinolin-4-amine $(3.22 \mathrm{mmol})$ yielded after $5.5 \mathrm{~h}$ microwave irradiation at $120^{\circ} \mathrm{C}$ and extraction with tert-butylmethyl ether a residue. This was purified by $\mathrm{CC}\left(\mathrm{CH}_{2} \mathrm{Cl}_{2}: \mathrm{CH}_{3} \mathrm{OH}=10: 1\right.$, Alox neutral) giving $62 \mathrm{mg}$ of $\mathbf{1 0 b}(18 \%)$ as a white-yellow amorphous solid. $R_{\mathrm{f}}=0.26\left(\mathrm{CH}_{2} \mathrm{Cl}_{2}: \mathrm{CH}_{3} \mathrm{OH}=10: 1\right.$, Alox neutral); ${ }^{1} \mathrm{H}$ NMR (DMSO- $d_{6}, 400 \mathrm{MHz}$ ): $\delta=2.32$ (br, s, $3 \mathrm{H}$, $\mathrm{CH}_{3}$ ), 3.47-3.50 (m, 2H, H-3'), 3.56-3.70 (m, 2H, H-2'), 6.64-6.80 (m, 1H, ArH), 7.09 (s, 1H, H-5), 7.33-7-56 (m, $5 \mathrm{H}, 2 \mathrm{NH}, \mathrm{ArH}), 7.76(\mathrm{~s}, 1 \mathrm{H}, \mathrm{ArH}), 8.08(\mathrm{~d}, J=8.3 \mathrm{~Hz}, 2 \mathrm{H}$, $\mathrm{ArH}), 8.14$ (br, s, $1 \mathrm{H}, \mathrm{ArH}), 8.34-8.38(\mathrm{~m}, 1 \mathrm{H}, \mathrm{ArH}) \mathrm{ppm}$; ${ }^{13} \mathrm{C}$ NMR (DMSO- $\left.d_{6}, 100 \mathrm{MHz}\right): \delta=23.94\left(\mathrm{CH}_{3}\right), 38.81$ (C-2'), 42.01 (C-3'), 98.98 (ArC), 105.47 (C-5), 117.63 $\left(\mathrm{ArC}_{\mathrm{q}}\right), 124.12,127.72,128.70,128.93$ (ArC), 133.54, 135.32, 149.29, $150.33\left(\mathrm{ArC}_{\mathrm{q}}\right), 152.07$ (ArC), $162.24(\mathrm{C}-4)$, 162.70 (C-2), 168.63 (C-6) ppm; IR (KBr): $\bar{v}=3433,3268$, 2927, 1577, 1556, 1492, 1456, 1371, 1342, 1330, 1239, 1140, 1092, 1013, $808 \mathrm{~cm}^{-1}$; HRMS (EI+): $\mathrm{m} / \mathrm{z}$ calcd. $\left(\mathrm{C}_{22} \mathrm{H}_{19} \mathrm{Cl}_{2} \mathrm{~N}_{5}\right)\left[\mathrm{M}^{+}\right]$423.1017, found 423.1056.

7-Chloro- $N$-[2-[[4-methyl-6-(4-methylphenyl)pyrimidin-2-yl]amino]ethyl]quinolin-4-amine (10c, $\mathrm{C}_{23} \mathrm{H}_{22} \mathrm{CIN}_{5}$ ) Reaction of $200 \mathrm{mg}$ of $\mathbf{5 c}(0.76 \mathrm{mmol})$ in $4 \mathrm{~cm}^{3}$ of dry THF with $676 \mathrm{mg}$ of $\mathrm{N}$-(2-aminoethyl)-7-chloroquinolin-4-amine (3.05 mmol) yielded after $7 \mathrm{~h}$ microwave irradiation at $120{ }^{\circ} \mathrm{C}$ and extraction with $\mathrm{CH}_{2} \mathrm{Cl}_{2}$ a residue. This was purified by $\mathrm{CC}\left(\mathrm{CH}_{2} \mathrm{Cl}_{2}: \mathrm{CH}_{3} \mathrm{OH}=40: 1\right.$, Alox neutral $)$ giving $133 \mathrm{mg}$ of 10c (43\%) as an off-white amorphous solid. $R_{\mathrm{f}}=0.27\left(\mathrm{CH}_{2} \mathrm{Cl}_{2}: \mathrm{CH}_{3} \mathrm{OH}=40: 1\right.$, Alox neutral $) ;{ }^{1} \mathrm{H} \mathrm{NMR}$ (DMSO- $\left.d_{6}, 400 \mathrm{MHz}\right): \delta=2.31$ (br, s, $3 \mathrm{H}, \mathrm{CH}_{3}$ ), 2.36 (s, $3 \mathrm{H}, \mathrm{ArCH}_{3}$ ), 3.47-3.50 (m, 2H, H-3'), 3.54-3.71 (m, 2H, 
H-2'), 6.59-6.88 (m, 1H, ArH), 7.04 (s, 1H, H-5), 7.257.31 (m, 4H, ArH, NH), 7.45 (t, $J=4.9 \mathrm{~Hz}, 1 \mathrm{H}, \mathrm{NH}), 7.77$ (br, s, 1H, ArH), 7.97-7.99 (m, 2H, ArH), 8.13 (br, s, 1H, ArH), 8.30-8.45 (m, 1H, ArH) ppm; ${ }^{13} \mathrm{C}$ NMR (DMSO$\left.d_{6}, 100 \mathrm{MHz}\right): \delta=21.15\left(\mathrm{ArCH}_{3}\right), 24.06\left(\mathrm{CH}_{3}\right), 39.25$ (C-2'), 42.49 (C-3'), 98.95 (ArC), 105.24 (C-5), 117.60 $\left(\mathrm{ArC}_{\mathrm{q}}\right), 124.11,124.20,126.89,127.73,129.48$ (ArC), 133.54, 134.72, 140.39, 149.28, $150.34\left(\mathrm{ArC}_{\mathrm{q}}\right), 152.06$ (ArC), 162.70 (C-2), 163.45 (C-6), 168.14 (C-4) ppm; IR (KBr): $\bar{v}=3264,2924,1582,1513,1447,1431,1369,1347$, 1330, 1239, 1140, 810, $802 \mathrm{~cm}^{-1}$; HRMS (EI +): $\mathrm{m} / z$ calcd. $\left(\mathrm{C}_{23} \mathrm{H}_{22} \mathrm{ClN}_{5}\right)\left[\mathrm{M}^{+}\right]$403.1564, found 403.1579.

7-Chloro-N-[2-[[4-(4-methoxyphenyl)-6-methylpyrimidin-2-yl]amino]ethyl]quinolin-4-amine (10d, $\left.\mathrm{C}_{23} \mathrm{H}_{22} \mathrm{ClN}_{5} \mathrm{O}\right)$ Reaction of $200 \mathrm{mg}$ of $\mathbf{5 d}(0.72 \mathrm{mmol})$ in 4 $\mathrm{cm}^{3}$ of dry THF with $637 \mathrm{mg}$ of $\mathrm{N}$-(2-aminoethyl)-7-chloroquinolin-4-amine $(2.87 \mathrm{mmol})$ yielded after $7 \mathrm{~h}$ microwave irradiation at $120{ }^{\circ} \mathrm{C}$ and extraction with $\mathrm{CH}_{2} \mathrm{Cl}_{2}$ a residue. This was purified by $\mathrm{CC}\left(\mathrm{CH}_{2} \mathrm{Cl}_{2}: \mathrm{CH}_{3} \mathrm{OH}=60: 1\right.$, Alox neutral) giving $194 \mathrm{mg}$ of $\mathbf{1 0 d}(64 \%)$ as a yellowish amorphous solid. $R_{\mathrm{f}}=0.20\left(\mathrm{CH}_{2} \mathrm{Cl}_{2}: \mathrm{CH}_{3} \mathrm{OH}=60: 1\right.$, Alox neutral); ${ }^{1} \mathrm{H}$ NMR (DMSO- $\left.d_{6}, 400 \mathrm{MHz}\right): \delta=2.31$ (br, s, $3 \mathrm{H}, \mathrm{CH}_{3}$ ), 3.47-3.50 (m, 2H, H-3'), 3.54-3.72 (m 2H, H-2'), $3.82\left(\mathrm{~s}, 3 \mathrm{H}, \mathrm{OCH}_{3}\right), 6.59-6.87(\mathrm{~m}, 1 \mathrm{H}, \mathrm{ArH}), 7.02-7.04(\mathrm{~m}$, $3 \mathrm{H}, \mathrm{H}-5, \mathrm{ArH}), 7.22(\mathrm{t}, J=5.9 \mathrm{~Hz}, 1 \mathrm{H}, \mathrm{NH}), 7.27-7.43(\mathrm{~m}$, $1 \mathrm{H}, \mathrm{ArH}), 7.45$ (t, $J=5.1 \mathrm{~Hz}, 1 \mathrm{H}, \mathrm{NH}), 7.77$ (s, 1H, ArH), $8.05(\mathrm{~d}, J=8.1 \mathrm{~Hz}, 2 \mathrm{H}, \mathrm{ArH}), 8.14$ (br, s, $1 \mathrm{H}, \mathrm{ArH}), 8.32-$ $8.44(\mathrm{~m}, 1 \mathrm{H}, \mathrm{ArH}) \mathrm{ppm} ;{ }^{13} \mathrm{C}$ NMR (DMSO- $\left.d_{6}, 100 \mathrm{MHz}\right)$ : $\delta=24.18\left(\mathrm{CH}_{3}\right), 38.92\left(\mathrm{C}-2^{\prime}\right), 42.58\left(\mathrm{C}-3^{\prime}\right), 55.52\left(\mathrm{OCH}_{3}\right)$, $98.95(\mathrm{ArC}), 104.76(\mathrm{C}-5), 114.22(\mathrm{ArC}), 117.59\left(\mathrm{ArC}_{\mathrm{q}}\right)$, 124.11, 124.20, 127.71, 128.49 (ArC), 129.68, 133.55, 149.26, $150.34\left(\mathrm{ArC}_{\mathrm{q}}\right), 152.06(\mathrm{ArC}), 161.36\left(\mathrm{ArC}_{\mathrm{q}}\right), 162.65$ (C-2), 163.18 (C-4), 168.06 (C-6) ppm; IR (KBr): $\bar{v}=3265$, 2929, 1579, 1559, 1510, 1457, 1437, 1371, 1342, 1331, 1251, 1240, 1178, 1031, $807 \mathrm{~cm}^{-1}$; HRMS (EI+): $\mathrm{m} / z$ calcd. $\left(\mathrm{C}_{23} \mathrm{H}_{22} \mathrm{ClN}{ }_{5} \mathrm{O}\right)\left[\mathrm{M}^{+}\right]$419.1513, found 419.1529.

\section{In vitro assays}

The in vitro growth inhibition assay of $P$. falciparum $K_{l}$ was performed according to an established procedure [25]. The in vitro growth inhibition assay of $P$. falciparum NF54 and the in vitro growth inhibition assay of Trypanosoma $b$. rhodesiense, as well as the assay for the determination of cytotoxicity against L6-cells were performed as described earlier [26].

Funding Open access funding provided by University of Graz.

Open Access This article is licensed under a Creative Commons Attribution 4.0 International License, which permits use, sharing, adaptation, distribution and reproduction in any medium or format, as long as you give appropriate credit to the original author(s) and the source, provide a link to the Creative Commons licence, and indicate if changes were made. The images or other third party material in this article are included in the article's Creative Commons licence, unless indicated otherwise in a credit line to the material. If material is not included in the article's Creative Commons licence and your intended use is not permitted by statutory regulation or exceeds the permitted use, you will need to obtain permission directly from the copyright holder. To view a copy of this licence, visit http://creativecommons.org/licenses/by/4.0/.

\section{References}

1. Akinsolu FT, Nemieboka PO, Njuguna DW, Ahadji MN, Dezso D, Varga O (2019) Int J Environ Res Public Health 16:1925

2. Holota S, Kryshchyshyn A, Derkach H, Trufin Y, Demchuk I, Gzella A, Grellier P, Lesyk R (2019) Bioorg Chem 86:126

3. Kennedy PGE (2006) Int J Parasitol 36:505

4. WHO (2019) World Malaria Report 2019. World Health Organization, Geneva

5. van der Pluijm RW, Imwong M, Chau NH, Hoa NT, Thuy-Nhien NT, Thanh NV, Jittamala P, Hanboonkunupakarn B, Chutasmit K, Saelow C, Runjarern R, Kaewmok W, Tripura R, Peto JT, Yok S, Suon S, Sreng S, Mao S, Oun S, Yen S, Amaratunga C, Lek D, Huy R, Dhorda M, Chotivanich K, Ashley EA, Mukaka M, Waithira N, Cheah PY, Maude RJ, Amato R, Pearson RD, Gonçalves S, Jacob CG, Hamilton WL, Fairhurst RM, Tarning J, Winterberg M, Kwiatkowski DP, Pukrittayakamee S, Hien TT, Day NPJ, Miotto O, White NJ, Dondorp AM (2019) Lancet Infect Dis 201:952

6. Curd FHS, Rose FL (1946) J Chem Soc 343

7. Curd FHS, Davis MI, Rose FL (1946) J Chem Soc 351

8. Curd FHS, Richardson DN, Rose FL (1946) J Chem Soc 378

9. Curd FHS, Davis MI (1946) J Chem Soc 370

10. Basford FR, Curd FHS, Rose FL (1946) J Chem Soc 713

11. Curd FHS, Davis MI (1946) J Chem Soc 720

12. Hull R, Lovell BJ (1947) J Chem Soc 41

13. Christian DJ, Bhoi MN, Borad MA, Rajani DP, Rajani SD, Patel HD (2014) World J Pharm Pharm Sci 3:1955

14. Seebacher W, Faist J, Presser A, Weis R, Saf R, Kaserer T, Temml V, Schuster D, Ortmann S, Otto N, Bauer R (2015) Eur J Med Chem 101:552

15. Singh K, Kaur H, Chibale K, Balzarini J, Little S, Bharatam PV (2012) Eur J Med Chem 52:82

16. Hoffelner M, Petritsch M, Ahmad S, Seebacher W, Dolensky J, Hochegger P, Kaiser M, Mäser P, Saf R, Weis R (2019) Monatsh Chem 150:1959

17. Zigeuner G, Hamberger H, Ecker R (1970) Monatsh Chem 101:881

18. Gotor V, Brieva R, Foces-Foces MC, Cano FH (1989) Tetrahedron 45:1783

19. Wendelin W, Schermanz K, Schweiger K, Fuchsgruber A (1983) Monatsh Chem 114:1371

20. Lu W, Liu Y, Ma H, Zheng J, Tian S, Sun Z, Luo L, Li J, Zhang H, Yang Z-J, Zhang X (2017) ACS Chem Neurosci 8:1980

21. Goswami S, Jana S, Dey S, Adak AK (2007) Aust J Chem 60:120

22. Yu Z, Chen F (1990) Yingyong Huaxue 7:54

23. Yu Z, Chen F (1991) Chem Abstr 114:185428

24. Chauhan SMS, Junjappa H (1976) Tetrahedron 32:1911

25. Seebacher W, Wolkinger V, Faist J, Kaiser M, Brun R, Saf R, Bucar F, Gröblacher B, Brantner A, Merino V, Kalia Y, Scapozza L, Perozzo R, Weis R (2015) Bioorg Med Chem Lett 25:1390

26. Mohsin N-ul-A, Seebacher W, Faist J, Hochegger P, Kaiser M, Mäser P, Saf R, Weis R (2018) Monatsh Chem 149:99

Publisher's Note Springer Nature remains neutral with regard to jurisdictional claims in published maps and institutional affiliations. 